\title{
1 Measuring root system traits of wheat in 2D images to 2 parameterize 3D root architecture models
}

3 Magdalena Landl (1)*, Andrea Schnepf (1), Jan Vanderborght (1), A. Glyn Bengough (2, 3), Sara L. Bauke (4),

4 Guillaume Lobet (1), Roland Bol (1) and Harry Vereecken (1)

\section{Affiliation}

(1) Forschungszentrum Juelich GmbH, Agrosphere (IBG-3), D- 52428 Juelich, Germany

(2) The James Hutton Institute, Invergowrie, Dundee, DD2 5DA, UK

(3) School of Science and Engineering, University of Dundee, Dundee DD1 4HN, UK

(4) Institute of Crop Science and Resource Conservation (INRES) - Soil Science and Soil Ecology, University of

14 *Corresponding author:

15 Magdalena Landl

16 Forschungszentrum Juelich GmbH, Agrosphere (IBG-3)

17 D- 52428 Juelich, Germany

18 Tel.: +49 2461618835

19 Fax: +492461612518

20 m.landl@fz-juelich.de

22 Number of text pages: 32

23 Number of tables: 6

24 Number of figures: 16 

system architecture

\section{Abstract}

Background and aims The main difficulty in the use of 3D root architecture models is correct parameterization. We evaluated distributions of the root traits inter-branch distance, branching angle and axial root trajectories from contrasting experimental systems to improve model parameterization.

Methods We analyzed 2D root images of different wheat varieties (Triticum Aestivum) from three different sources using automatic root tracking. Model input parameters and common parameter patterns were identified from extracted root system coordinates. Simulation studies were used to (1) link observed axial root trajectories with model input parameters (2) evaluate errors due to the 2D (versus 3D) nature of image sources and (3) investigate the effect of model parameter distributions on root foraging performance.

Results Distributions of inter-branch distances were approximated with lognormal functions. Branching angles showed mean values $<90^{\circ}$. Gravitropism and tortuosity parameters were quantified in relation to downwards reorientation and segment angles of root axes. Root system projection in 2D increased the variance of branching angles. Root foraging performance was very sensitive to parameter distribution and variance.

Conclusions 2D image analysis can systematically and efficiently analyze root system architectures and parameterize

43 3D root architecture models. Effects of root system projection (2D from 3D) and deflection (at rhizotron face) on 44 size and distribution of particular parameters are potentially significant.

\section{Abbreviations}

$46 \beta$, root segment angle to the horizontal

$D_{e}$, diffusion coefficient of a solute in soil 
$\mu$, mean value

sg, sensitivity to gravitropism

std, standard deviation

$\theta$, branching angle in the vertical plane

\section{Introduction}

The efficiency of a plant root system to acquire below-ground resources predominantly depends on its root system architecture (Lynch 2007; Rich and Watt 2013; Smith and De Smet 2012). The complex process of root system development and its interaction with the soil matrix is, however, hard to study due to the opaque nature of the soil which makes direct measurements difficult. The use of three - dimensional root architecture models can thereby provide an opportunity to systematically investigate the influence of different environmental conditions and a wide range of crop management regimes on the formation and functionality of root systems, to interpret experimental data and to test hypotheses on root - soil interaction processes at different scales (Dunbabin et al. 2013; Roose and Schnepf 2008). In experimental field studies, such large scale testing approaches are impossible to realize. An important prerequisite for this simulation based investigation is that properties and behavior of the root system that define its functioning in soils under different conditions can be inferred from experimental data.

Over the years, several three-dimensional root architectural models have been developed: RootMap (Diggle 1988), R-SWMS (Javaux et al. 2008), RootBox (Leitner et al. 2010), SimRoot (Lynch et al. 1997), RootTyp (Pagès et al. 2004), SPACSYS (Wu et al. 2007). This diversity can be explained by the wide range of specific model objectives such as representation of architectural characteristics of different species (Diggle 1988; Pagès et al. 2004), analysis of interactions between root development and water and nutrient uptake (Dunbabin et al. 2002) or investigation of root growth in structured soil (Landl et al. 2017). The gross representation of root systems, however, is comparable

73 in all these models and they use similar root architectural parameter sets: While the total size of a root system is 
distribution of a root system depends essentially on branching angle and root growth trajectories of the main axes (Bingham and Wu 2011). Root growth trajectories of the main axes are determined by the directional orientation of newly developed root segments. Due to the ability to use both space and time dimensions as well as various model concepts, parameters that are used in models that generate root architectures can be defined in several ways. Table 1 gives an overview of the parameterization of the root traits inter-branch distance, branching angle and root growth trajectories of the main axes for several individual root architecture models.

Differences in the parameterization of root traits leads to changes in root system architecture, which significantly affects the ability of roots to forage the soil and thus the root nutrient uptake capacity (Fitter et al 1991; Pagès 2011). Correct parameterization of 3D root architecture models is thus crucial when evaluating root-soil interaction processes.

Root architecture parameterization techniques always represent a compromise between throughputs, precision, realistic representation of field root architectures and ease of data processing (Kuijken et al. 2015). While 3D imaging techniques such as x-ray computed tomography (Mooney et al. 2012; Tracy et al. 2012; Tracy et al. 2010) and magnetic resonance imaging (Pohlmeier et al. 2013; Rascher et al. 2011) allow non - invasive studying of the spatio - temporal dynamics of root growth, they still require elaborate data processing and are only suitable for relatively small and young root systems scanned at low throughput rate (Mairhofer et al. 2012; Nagel et al. 2012). Destructive sampling allows measurement of the whole root system, however, it is a time consuming and tedious work, natural root positions can hardly be kept and a large loss of fine roots must be accepted (Judd et al. 2015; Pagès and Pellerin 1994; Pellerin and Pagès 1994). In that sense, root parameterization via 2D image analysis represents a good alternative by allowing for various methods of image acquisition, high throughput and - due to recent developments of automated root tracking software - relatively simple processing (Delory et al. 2016; Leitner et al. 2014).

Various methods for the acquisition of 2D root images have been developed over the years: The first 2D representations of root system architecture were hand drawings (Kutschera 1960; Weaver et al. 1922; Weaver et al. 1924). The field grown root systems were thereby gradually excavated and simultaneously traced on sketching paper (Kutschera 1960). A recently-revived method to non-invasively image the development of root system architecture in 2D is that of imaging roots grown in rhizotrons, and specifically rhizotron boxes (Kuchenbuch and Ingram 2002; Nagel et al. 2012). Rhizotron boxes are soil filled containers with a transparent front plate that allows observing 4 

root architecture development, they spatially constrict the root system and allow only partial visibility of roots at the transparent front plate (Nagel et al. 2012; Nagel et al. 2015; Wenzel et al. 2001). A simple method that produces a large number of images with perfect visibility of the root system is represented by roots grown on germination paper (Atkinson et al. 2017; Atkinson et al. 2015). The absence of soil structure and soil mechanical impedance as well the

108 limited root age, however, cast doubt if the observed root architecture is a valid representation of root systems of 109 field grown plants (Clark et al. 2011; Hargreaves et al. 2009; Nagel et al. 2012).

110 In this study, we want to recover the root traits inter-branch distance, branching angle and root growth trajectories of 111 the main axes from various 2D root images of different wheat varieties (Triticum Aestivum). Model input parameters 112 and common parameter patterns are identified. In a series of simulation studies possible parameterization errors due 113 to the two-dimensionality of image sources as well as the influence of different parameterizations on root foraging 114 performance are evaluated.

\section{Methods}

116 Image Sources

117 We used root images from three different sources: hand drawings from literature, images from a rhizotron 118 experiment and images from roots grown on germination paper (Fig.1). The 11 hand drawings with image 119 resolutions between 85 and 270 ppi were selected from three different literature sources and represent root systems 120 of variable age and wheat varieties growing at diverse locations (Table 2). The rhizotron images with a resolution of 121300 ppi were obtained from an experimental study, in which spring wheat was grown under controlled laboratory 122 conditions in rhizotrons with inner dimensions of 50x30x3.5 cm. The lower part of the rhizotrons was filled with 123 compacted subsoil, the upper part with lose topsoil (bulk density $1.4 \mathrm{~g} \mathrm{~cm}^{-3}$ and $1 \mathrm{~g} \mathrm{~cm}^{-3}$ respectively). While the 124 experimental setup included different topsoil treatments with regard to phosphorus and water supply, we only used the images of the six control replicates where both phosphorus and water supply was sufficient. The rhizotron images were taken on day 41 after sowing, just before harvest. A detailed description of the experimental setup is given in

127 (Bauke et al. 2017). The images of roots grown on germination paper $(24 \times 30 \mathrm{~cm})$ with a resolution of 442 ppi were 128 obtained from an experimental study, where two different winter wheat cultivars ('Rialto' and 'Savannah') were 
grown in 41 respectively 39 replicates over a time period of 8 days under controlled lab conditions. A detailed description of the experimental setup is given in Atkinson et al. (2015).

Root system images were processed using the fully automatic root tracking software Root System Analyzer which is based on MATLAB (R2014b) (RSA; Leitner et al. 2014). The RSA saves detailed information on the coordinates of a root system in MATLAB mat-files. Analysis with the RSA requires images with continuous and clearly visible root systems. The rhizotron images, where only part of the total root system is visible at the transparent front plate of the rhizotron, thus had to be pre-processed prior to analysis. We used the open source tool GIMP 2.8 to segment the root systems manually. To keep error propagation from image segmentation to parameter determination at a minimum, we first only segmented those roots, which were clearly visible on the rhizotron image. These root systems were later used for recovering the parameters branching angle and axial trajectories. We then additionally inserted laterals, for which we had to estimate the location of the connection to their parent root. These extended root systems were later used for recovering the parameter inter-branch distance, which depends on the visibility of all lateral roots. from the extracted root system coordinates. The inter-branch distance was measured as the distance between two successive branches in centimeters. The branching angle was determined as the angle in the vertical plane between a branch and its parent root in degrees, which is measured at a certain distance from the point where the branch emerges. In one respect, this distance should be minimized to measure the initial branching angle; however, it also needs to be large enough to avoid inaccuracies in the computation process. We performed a small analysis based on artificial root systems with known ground truth and similar root radii, which suggested that a search radius of $0.5 \mathrm{~cm}$

150 distance from the branch point is suitable for correctly computing branching angles. Root growth trajectories of axial roots are determined by their initial growth angle from the horizontal and its dynamic changes from the root base to the root apex which is affected by numerous factors such as soil compaction (Popova et al. 2016), soil temperature

153 (Tardieu and Pellerin 1990) or soil water status (Nakamoto 1994). In a simplified way, the shape of a root trajectory 154 can be described by two features: its overall curvature and its small-scale waviness which is known as tortuosity 

segments of $1 \mathrm{~cm}$ length and determined for each segment its angle to the horizontal as well as its reorientation angle with respect to the previous root segment in degrees. We then calculated the relationship between growth angle and reorientation angle of individual root segments, which gives information on the curvature of a trajectory in relation to its inclination as well as on tortuosity.

Root parameters were quantified separately for each of the 11 root drawings. Root parameters derived from the six rhizotron images obtained from replicate experiments were pooled together to one group. Root parameters derived from images of roots grown on germination paper were classified into two groups according to cultivar ('Rialto': 39 images, 'Savannah': 41 images). Altogether, we analyzed root parameters from 14 different data sources. None of the used image sources allowed differentiating between seminal and shoot-born roots and only one order of lateral roots was identified. We therefore only distinguish between axial roots and first order laterals.

Among the different traits describing root architecture, root growth trajectories of axial roots are of particular importance for the shape of a root system. Their correct representation in 3D root architecture models is thus important to obtain plausible simulation results. In a first simulation study, we therefore tested the ability of different model approaches to reproduce our experimental findings on axial root trajectories and quantified model parameters for our analyzed root systems.

172 The recovery of 3D root architecture parameters from $2 \mathrm{D}$ images has the obvious drawback of losing the third 173 dimension. Images respectively drawings of root architectures are created by projecting the 3D root systems onto 2D

174 space. Root system architectures of plants grown in rhizotrons or on germination paper are affected by root 175 deflection due to spatial growth constraints. While this has no influence on the parameter inter-branch distance, both 176 branching angle and axial root growth trajectories are affected. In a second simulation study, we therefore analyzed 177 the effects of projection and deflection, respectively, on the parameters branching angle and axial root growth 178 trajectories.

179 Root architecture significantly influences root foraging performance by determining the volume of soil that can be explored by roots (Fitter et al. 1991; Pagès 2011). In a third simulation study, we evaluated the effect of different 
parameterizations of our focus root architecture parameters inter-branch distance, branching angle and axial root growth trajectories on the foraging performance of root systems.

Simulation study 1: Ability of 3D root architecture models to reproduce experimental observations on axial root trajectories

In 3D root architecture models, root growth trajectories are composed of individual root segments. At each root growth time step, a new segment emerges whose directional orientation must be determined with regard to overall curvature and tortuosity. Most root architecture models (SimRoot, RootTyp, SPACSYS, R-SWMS) use a vectorbased approach, where the directional orientation of an individual root segment is calculated from a vector expressing tortuosity and a vector expressing gravitropism. 2D root images represent root systems in the xz-plane and thus provide information on root curvature and root tortuosity in vertical, but not in horizontal direction. To test the ability of the vector-based approach to reproduce observations of axial root trajectories on 2D root images, we thus converted the $3 \mathrm{D}$ equation to $2 \mathrm{D}$ space:

$$
\vec{d}=\left(\begin{array}{l}
d x_{\beta, \delta} \\
d z_{\beta, \delta}
\end{array}\right)+s g *\left(\begin{array}{c}
0 \\
-1
\end{array}\right) .
$$

The first term on the right hand side represents the growth direction vector of the preceding root segment $\mathrm{dx}_{\beta}$ with unit length 1 which is deflected by the random angle $\delta$; the second term expresses the gravitropism component with sg as gravitropism sensitivity factor. The random deflection angle $\delta$ is a normally distributed random angle with mean zero and unit standard deviation $\sigma$. The unknown parameters are thus the sensitivity to gravitropism sg and the standard deviation of the random deflection angle $\sigma$ (cf. Clausnitzer and Hopmans (1994)). We implemented this formula in MATLAB and computed root trajectories using 7 different parameterizations of sg and 21 different parameterizations of $\sigma$ (147 parameter combinations altogether, values are given in Table 3 ). For each parameter combination, we simulated 50 axial root trajectories with individual lengths of $50 \mathrm{~cm}$ (example in Fig.2).

Simulation study 2: Effects of projection and deflection on the parameters branching angle and axial root growth trajectories.

The objective of this study was to analyze the effects of projection and deflection, respectively, on the parameters branching angle and axial root growth trajectories. 
Root system development was simulated using the MATLAB version of the 3D root architecture model RootBox, which is fully described in Leitner et al. (2010) and shall here only be addressed briefly. RootBox defines each root order by a set of different model parameters. Basal and apical root zone determine the length of the unbranched zone before the first and after the last branch, respectively. Inter-branch distance defines the distance between two successive branches and thereby also affects the maximum root length for a given number of branches. Root growth speed is described by a negative exponential function whose initial slope is determined by the initial elongation rate

212 and whose asymptote depends on the maximum root length. The emergence angle of axial roots respectively the 213 initial angle between a branch and its parent root is defined by a radial angle in the horizontal plane, and an insertion 214 respectively branching angle in the vertical plane. The radial angle is generally drawn at random between 0 and $2 \pi$, 215 but can also be set to a specific angle to consider non-independence of branching files. To describe axial root growth 216 trajectories, we implemented the vector-based approach used in most root architecture models (SimRoot, RootTyp, 217 SPACSYS, R-SWMS) into RootBox: In this approach, newly emerged root segments are oriented according to the 218 direction of the previous root segment, sensitivity to gravitropism and random angle deflection.

219 To evaluate the effect of projection, we mapped the unconstrained 3D root system onto the $\mathrm{x}-\mathrm{z}$ plane. To evaluate the 220 effect of deflection, we simulated a root system, which was spatially constrained by a rhizotron with dimensions of 20x2x30 cm (Fig.3). This geometry is implemented based on signed distance functions in which the distance of a given point to the closest boundary is evaluated and given a positive sign if located inside the geometry and a negative sign if located outside. Random optimization ensures that the new position of a growing root tip is always inside the rhizotron domain (Leitner et al. 2010). Using the coordinates of these root systems, we then computed (1) branching angles between laterals and their parent roots and (2) relationships between angle to the horizontal and reorientation angle of individual root segments.

Simulation study 3: Influence of different parameterizations of inter-branch distance, branching angle and axial root trajectories on foraging performance of a root system

Root system development was simulated using the MATLAB version of the 3D root architecture model RootBox with an alternative approach for the simulation of axial root growth trajectories as described in simulation study 2.

The soil volume around a root system available for nutrient uptake, i.e. the rhizosphere, was computed using the approach by Fitter et al. (1991). For this procedure, a very fine 3D grid is overlaid on the root system. The center of 
every grid cell is then scanned for its distance to the nearest root segment. If the distance is smaller than a specified rhizosphere radius $R_{\text {rhiz, }}$, the grid cell volume is counted as rhizosphere volume. The rhizosphere radius $R_{\text {rhiz }}$ is determined by the effective diffusion coefficient of a solute in soil and the age of the respective root segment and calculated according to Nye and Tinker (1977) as

$$
R_{\text {rhiz }}=r+2 \sqrt{D_{e} t}
$$

where $r$ is the radius of the root segment $(\mathrm{cm}), D_{e}$ is the effective diffusion coefficient in soil $\left(\mathrm{cm}^{2} \mathrm{~s}^{-1}\right)$ and $\mathrm{t}$ is the root segment age (s). To evaluate the influence of different soil diffusion coefficients $\left(D_{e}\right)$ on the rhizosphere volume, we performed simulations with three different $D_{e}$ values: $10^{-8}, 10^{-7}$ and $2 \times 10^{-6} \mathrm{~cm}^{2} \mathrm{~s}^{-1}$. The first two values are typical effective phosphorus diffusion coefficients in soil, which account for the effect of sorption of phosphorus to soil particles (Schenk and Barber 1979); the latter one is a characteristic nitrate diffusion coefficient of the soil (Volder et al. 2005). While the net rhizosphere volume was defined as the volumetric sum of all unique grid cells, the rhizosphere volume with overlap was specified as the volumetric sum of all - partially multiply assigned - grid cells. The overlap volume is then the difference between rhizosphere volume with overlap and net rhizosphere volume (Fig.4). Considering that both rhizosphere and overlap volume are absolute values and depend on the total size of a root system, we introduced the parameter inter-root competition (IRC) as a size-independent measure of comparison following the approach by $\mathrm{Ge}$ et al. (2000). IRC is calculated as

$$
I R C=\frac{V_{\text {overlap }}}{V_{\text {rhizo }}} * 100 \%
$$

where $\mathrm{V}_{\text {overlap }}$ is the overlap volume and $\mathrm{V}_{\text {rhizo }}$ is the net rhizosphere volume. Fig.5 shows an example of a simulated root system and its surrounding rhizosphere volume for different values of $\mathrm{D}_{\mathrm{e}}$.

Using observations from root image analysis, we identified factors that can be used to differently parameterize our three focus parameters. These factors were mean and standard deviation for both inter-branch distance and branching angle and standard deviation of the random angle deflection respectively sensitivity to gravitropism for the parameter axial root growth trajectories. For each of these factors, we defined variation intervals with lower and upper bounds. For the parameter inter-branch distance, we used probability distribution as an additional categorical factor of variation, which was set to either normal or lognormal distribution. Descriptive statistics of the lognormal distribution were calculated by transformation from the parameters of the normal distribution. The domain of the 
normal distribution was restricted to the positive number range; negative values were set to $10^{-6} \mathrm{~cm}$. We also

260 included a categorical factor of variation for the radial alignment of $1^{\text {st }}$ order laterals around the main axis. In

261 literature, the alignment of lateral roots around the root axis is still unclear. While Abadia-Fenoll et al. (1986) and

262 Barlow and Adam (1988) found lateral roots of onion and tomato to form in acropetal sequence around their parent

263 axis, Pellerin and Tabourel (1995) and Yu et al. (2016) observed an unpredictable radial emergence pattern for lateral

264 roots of maize and wheat. Due to these inconsistencies, we specified the radial angle either as random in the interval

$265[02 \pi]$ or set it to a value of $45^{\circ}$ (sequential acropetal branching from 8 phloem poles around the axis). Variation

266 intervals for parameterization factors as well as descriptions of the additional factors are given in Table 4. The

267 remaining root growth parameters were set to fixed values, which were either derived from literature or directly from

268 our analyzed root images (Table 5). We considered two orders of lateral roots. The simulation time was set to 30

269 days and each root system consisted of 7 axial roots.

270 For all possible combinations of categorical factors, we then performed 1000 root system realizations that 271 corresponded with 1000 parameter sets that were randomly drawn from the intervals specified in Table 4 . This gave 272 a total of 4000 root system realizations (i.e. $2^{2} \mathrm{x} 1000$ ). For each root system, we then computed inter-root competition 273 as a measure of foraging performance for all three soil diffusion coefficients $\left(D_{e}\right)$ defined above. Relationships 274 between inter-root competition and our focus parameters were explored by means of scatterplots. To visualize the 275 main trends, we fitted linear regression lines. Correlation analyses were then used to quantitatively evaluate the 276 linear relationship between inter-root competition and our focus parameters.

277 Statistics

278 Statistical analyses were performed with MATLAB (R2014b). To evaluate differences in means with unequal variance, a Welch's t-test was used. To analyze differences in variances, we performed a two-sample F-test. Linear

280 regression relationships were evaluated by means of an F-test. In the following, significant results correspond to $281 \mathrm{p}<0.05$, while highly significant results represent $\mathrm{p}<0.01$. 
The relationships between inter-branch distance and distance along the root axis are very scattered for all data sources with values ranging from close to $0 \mathrm{~cm}$ to up to $3 \mathrm{~cm}$. An F-test showed a significant increase in inter-branch distance from the base of the branched zone down to the root apex for 11 out of 14 data sets, no trend for two data sets and a decrease for one data set (Fig.6). The large variability of inter-branch distances observed for the data source from rhizotron images can be explained by the only partial visibility of the root system which has probably obscured some lateral roots. The global distributions show for all data sources a highly asymmetrical shape which can be well described with lognormal distributions (Fig.7). We observed a large percentage of short inter-branch distances with medians ranging between 0.1 and $0.5 \mathrm{~cm}$ (Fig.8). No systematic pattern was apparent with regard to

292 the different data sources.

Branching angle

The global distribution of branching angles shows a bell shape for the roots grown on germination paper that can be approximated with a normal distribution; for the remaining data sources, the distribution of branching angles is spread more widely and shows positive skewness (Fig.9). Interestingly, branching angles from all data sources show similar medians that range from $59.5^{\circ}$ to $79.4^{\circ}$ and are well below $90^{\circ}$ (Fig.10).

Root growth trajectories of axial roots were reconstructed for all root systems of each data source from the extracted root coordinates prior to analysis (Fig.11). all but one data source meaning that more horizontally growing roots generally reoriented stronger towards the vertical than more perpendicularly growing ones (Fig.12). An F-test showed that this correlation was highly significant for 3, significant for 5 and not significant for 6 data sources. Not significant relationships can be an indicator for abrupt changes in the growth path (e.g. the rightmost trajectory in Fig 11a), high root tortuosity or liminal growth angles that deviate from the vertical (Nakamoto 1994). The reorientation angle $\Delta \beta$ at a segment angle 
of $\beta=-90^{\circ}$ (vertical root growth) predicted by regression tended for all data sources towards zero suggesting that gravitropism is the predominant influence factor in the formation of trajectory curvature. While the slope of the regression line is a measure of gravitropism, the standard error of the estimate determines the degree of root tortuosity. The slope of the regression lines ranged between 0 and -0.2 ; the standard error of the estimate between $7.7^{\circ}$ and $21.8^{\circ}$. With regard to different data sources, we did not find any systematic pattern of slope; standard

312 errors of the estimate, however, were highest for root drawings of large, mature root systems and lowest for roots

313 grown on germination paper.

\section{Simulation studies}

315 Simulation study 1: Ability of 3D root architecture models to reproduce experimental observations on axial root 316 trajectories

317 For each combination of parameters describing gravitropism and tortuosity, we calculated the relationship between 318 reorientation angle $\Delta \beta$ and angle of the previous $1 \mathrm{~cm}$ long root segment $\beta$ and approximated it with a linear 319 regression line. The results are shown in Fig.13 for 20 selected parameter combinations. The standard deviation of 320 the random deflection angle $\sigma$ can be seen as a direct measure of the standard error of the estimate and thus tortuosity 321 if the influence of gravitropism is not too strong. Large values of gravitropism force the root tip to grow towards the 322 vertical and result in standard errors of the estimate smaller than $\sigma$. The gravitropism parameter sg is inversely proportional to the slope of the regression line. The prediction with the regression lines, which are close to $0^{\circ}$ at $\beta=$ -

$32490^{\circ}$, reflect the minimum average reorientation of vertically oriented roots. An F-test showed that correlations 325 between reorientation angle and angle of the previous $1 \mathrm{~cm}$ long root segment were highly significant for all 326 combinations, except for the combination of the largest root tortuosity and smallest gravitropism value. The relationships between root reorientation and root angle resemble those calculated for our image-derived axial root trajectories (Fig.12). The approach is thus well suited to simulate curvature and tortuosity of wheat root trajectories.

To link the model parameters necessary for the simulation of root trajectories (sensitivity to gravitropism sg and root tortuosity $\sigma$ ) to the relationship between root reorientation and root segment angle, we calculated characteristic curves for the different parameter combinations (Fig.14). The characteristic curves are the smoothed connection lines between the properties of the regression lines (standard error of the estimate and slope) that relate segment angles and reorientation angles of axial root trajectories for each parameter combination. Figure 14 shows that slope and 
standard error of the regression cannot be mapped linearly to the parameters $\sigma$ and $\mathrm{sg}$ that describe gravitropism and tortuosity. To quantify model parameters for our observed root trajectories, we inserted the regression line properties deduced from Fig.12 into the graphs and located their positions. This gave us values between 0.01 and 0.3 for the sensitivity to gravitropism sg and values between 9 and $20^{\circ} \mathrm{cm}^{-1}$ for the unit standard deviation of the random angle $\sigma$.

Simulation study 2: Effects of projection and deflection on the parameters branching angle and axial root growth trajectories.

While mean branching angles of projected and deflected root systems did not differ significantly from branching angles of the unconstrained 3D root system, their variance was significantly higher. This was especially true for the projected root system (Fig.15-1). The similarity in mean branching angles can be explained by the symmetrical alignment of lateral roots around the root axis, which leads to a compensation between positive and negative angle deviations due to projection or deflection. Relationships between reorientation angle and angle of the previous $1 \mathrm{~cm}$ long root segment differed significantly between projected and deflected root systems and the unconstrained 3D root system with regard to slope and thus gravitropic root growth. With regard to standard deviation of the estimate and thus tortuosity, only the projected, but not the deflected root system showed a significantly higher value than the unconstrained 3D root system (Fig.15-2). Considering that absolute deviations are rather small, these discrepancies in gravitropism and tortuosity are negligible in terms of model parameterization.

Simulation study 3: Influence of different parameterizations of inter-branch distance, branching angle and axial root trajectories on foraging performance of a root system

We found clear relationships between inter-root competition and different parameterizations. These relationships are illustrated for $D_{e}=10^{-8} \mathrm{~cm}^{2} \mathrm{~s}^{-1}$ in Fig.16. In each plot, all simulation results were plotted against the specific parameter. In Table 6, correlation coefficients show the significance of linear relationships between inter-root competition and parameters. As expected, IRC decreased with increasing mean inter-branch distance. If mean interbranch distance was low, IRC was significantly higher for lognormally than for normally distributed inter-branch distances. Regular alignment of laterals around the main axis tended to less IRC than random alignment, however, not significantly. The relationship between IRC and mean inter-branch distance was significantly weaker for the largest soil diffusion coefficient. The effect of varying standard deviation of inter-branch distance on IRC was 
surprising: For lognormally distributed inter-branch distances IRC increased with increasing standard deviation; for normally distributed inter-branch distances, it decreased. These relationships remained nearly constant for all soil diffusion coefficients. IRC decreased with increasing mean branching angle. This effect, however, was only significant for the lowest soil diffusion coefficient. Larger standard deviations of the branching angle led to a significant increase in IRC for the lower two soil diffusion coefficients. This effect was larger for regularly aligned laterals than for randomly aligned ones. Greater values of standard deviation of the random angle deflection led to lower IRC. This effect, however, was only significant for the largest soil diffusion coefficient. As expected, larger values of sensitivity to gravitropism led to more IRC. This effect was stronger for larger soil diffusion coefficients and also for root systems with normally distributed inter-branch distances as compared with lognormally distributed ones.

\section{Discussion}

372 2D image analysis is a simple and fast way to retrieve information on root system architectures for the 373 parameterization of 3D root architecture models. The systematic analysis of root images from three different sources 374 (root drawings, rhizotron images, images of roots grown on germination paper) allowed us to identify universally 375 occurring parameter patterns of wheat roots.

Observed patterns of root architecture parameters contrast common model assumptions

Inter-branch distance along axial roots predominantly increased with increasing distance from the base of the branched zone. But in some cases, it also remained constant or decreased. These results are in line with published data: While inter-branch distance along the axial roots was frequently observed to increase with increasing distance from the base of the branched zone (e.g. maize by Ito et al. (2006), Pagès and Pellerin (1994), Postma et al. (2014) and pea by Tricot et al. (1997)), other studies found constant or no identifiable pattern of inter-branch distance along axial roots (e.g. wheat by Ito et al. (2006) and banana by Draye (2002)). Studies have proposed that soil compaction (Pagès and Pellerin 1994), oxygen gradients (Liang et al. 1996) or water availability in the vicinity of the root (Bao et al. 2014) may alter branching density and thus inter-branch distances. In 3D root architecture models, the phenomenon of varying inter-branch distances along axial roots could be considered by a coefficient that is linked to these processes. Our findings suggest that the global distribution of inter-branch distances of wheat roots follows a lognormal distribution, which is in line with observations by Pagès (2014) on roots of various species of the Poaceae 

architecture models where inter-branch distances are either set to a fixed value or drawn from a normal distribution (see Table 1).

The branching angle of lateral roots relative to their parent axis is a standard parameter that is included in all 3D root architecture models (Table 1) and defines the initial direction of the first segment of a lateral root at the point of emergence. Our findings suggest that branching angles of $1^{\text {st }}$ order laterals of wheat root systems are significantly smaller than $90^{\circ}$ with a variance that depends on the growth medium. This contrasts common model assumptions where branching angles are frequently set to a constant value of $90^{\circ}$ relative to the parent root for reasons of simplicity (Clausnitzer and Hopmans 1994; Pagès et al. 2004; Wu et al. 2005) or as a general model condition (Diggle 1988).

More horizontally growing roots reoriented stronger towards the vertical than more vertically growing roots with reorientation angles approaching $0^{\circ}$ as the roots turn to the vertical. These findings are in line with observations by Wu et al. (2015) on axial maize root trajectories. A number of axial root trajectories derived from root drawings did not follow a continuous gravitropic growth path, but changed their slope abruptly to the vertical after growing in relatively constant direction. Similar observations were reported by Tardieu and Pellerin (1990) who suggest that earthworm channels that can be used by roots as preferential growth paths might be responsible for this effect. Levels of root tortuosity showed a relatively clear ranking with tortuosity of root systems grown in structured soil > tortuosity of roots grown in sieved soil > tortuosity of roots grown on filter paper. While root age seems to have an influence, this effect is probably also caused by differences in the penetration resistance of the growth medium as proposed by Popova et al. (2016). A simulation study showed good agreement between simulated and observed curvature and tortuosity of axial wheat root trajectories. We developed characteristic curves that relate model input parameters with downwards reorientation and segment angles of axial trajectories. These characteristic curves can be used to calibrate the model parameters gravitropism and tortuosity from 2D root trajectories, which is a step forward in the realistic parameterization of 3D root architecture models.

412 Root system projection leads to overestimation of the variance of branching angles

413 The use of two-dimensional root drawings or rhizotron images for the parameterization of 3D root architecture 414 models is common practice (Delory et al. 2016; Doussan et al. 2006; Leitner et al. 2014; Pagès et al. 2004). To our 
415 knowledge, the effects of root system projection or deflection on size and distribution of 3D root architecture 416 parameters, however, has not yet been analyzed. We showed that projection greatly affects branching angles by 417 overestimating their variance. Effects of projection and deflection, respectively, on tortuosity and gravitropism 418 parameters were shown to be negligible. Root foraging performance depends strongly on parameter distribution and parameter variance

The influence of the main determinants of root architecture (e.g. mean inter-branch distance, mean branching angle) on root foraging performance is well documented in literature (Bingham and $\mathrm{Wu}$ 2011; Postma et al. 2014). The influence of parameter variance and distribution, however, which describes the degree to which stochasticity affects developmental processes, is much less explored (Forde 2009). In most 3D root architecture models, parameter stochasticity is not used or only used to a limited extent (Table 1). We could demonstrate the significant impact of variance in both inter-branch distance and branching angle on foraging performance of a root system. Also, the use of different distributions of inter-branch distance (normal, lognormal) led to significant differences in effective rhizosphere volume around a root system. Interestingly, differences in radial alignment of lateral roots around the root axis, i.e. random or acropetal branching, only led to minor differences in root foraging performance.

We chose the model approach by Nye and Tinker (1977) to compute the rhizosphere volume around a root system. This purely physical model assumes continuous nutrient uptake by individual root segments. Gao et al. (1998) and Bouma et al. (2001), however, showed that root segment age is inversely related to nutrient uptake capacity and that young roots therefore take up more nutrients than old roots. Inter-root competition is mainly caused by rhizosphere zone overlap of neighboring laterals, which are usually of similar age. Taking into account root segment agedependent nutrient uptake rates would therefore alter absolute values of root foraging performance, but not our described qualitative relationships and trends.

This study improves the capacity of modelers to simulate realistic root systems, which can be used to investigate root-soil interaction processes. Further investigations could include research on parameters that were not the focus of this study, but also greatly influence root foraging performance such as number of axial roots, axial insertion angle and length and distribution of lateral roots. More information on root architecture parameters for a range of plant species would also be desirable. Increased knowledge on plastic root response to soil heterogeneity and environmental changes would further improve 3D root architecture modeling. 
443 Funding by German Research Foundation within the Research Unit DFG PAK 888 is gratefully acknowledged. The

444 James Hutton Institute receives funding from the Scottish Government. We also thank Klaas Metselaar from the 445 Department of Environmental Sciences at Wageningen University, Netherlands, for providing high-resolution scans 446 of wheat root images from the Root Atlas. 
Abadia-Fenoll F, Casero P, Lloret P, Vidal M 1986 Development of lateral primordia in decapitated adventitious roots of Allium cepa. Ann. Bot. 58, 103-107

Atkinson JA, Lobet G, Noll M, Meyer PE, Griffiths M, Wells DM 2017 Combining semi-automated image analysis techniques with machine learning algorithms to accelerate large scale genetic studies. GigaScience 6, 1-7

Atkinson JA, Wingen LU, Griffiths M, Pound MP, Gaju O, Foulkes MJ, Le Gouis J, Griffiths S, Bennett MJ, King J 2015 Phenotyping pipeline reveals major seedling root growth QTL in hexaploid wheat. J. Exp. Bot. 66, 2283-2292

Bao Y, Aggarwal P, Robbins NE, Sturrock CJ, Thompson MC, Tan HQ, Tham C, Duan L, Rodriguez PL, Vernoux T, Mooney SJ, Bennett MJ, Dinneny JR 2014 Plant roots use a patterning mechanism to position lateral root branches toward available water. Proc. Natl. Acad. Sci. U. S. A.111, 9319-9324

Barlow P, Adam J 1988 The position and growth of lateral roots on cultured root axes of tomato,Lycopersicon esculentum (Solanaceae). Plant Syst. Evol. 158, 141-154

Bauke SL, Landl M, Koch M, Hofmann D, Nagel KA, Siebers N, Schnepf A, Amelung W 2017 Macropore effects on phosphorus acquisition by wheat roots - a rhizotron study. Plant Soil 416, 67-82

Bingham IJ, Wu L 2011 Simulation of wheat growth using the 3D root architecture model SPACSYS: validation and sensitivity analysis. Eur. J. Agron.34, 181-189

Bouma TJ, Yanai RD, Elkin AD, Hartmond U, Flores-Alva DE, Eissenstat DM 2001 Estimating age-dependent costs and benefits of roots with contrasting life span: comparing apples and oranges. New Phytol. 150, 685-695

Clark RT, MacCurdy RB, Jung JK, Shaff JE, McCouch SR, Aneshansley DJ, Kochian LV 2011 3-dimensional root phenotyping with a novel imaging and software platform. Plant Physiol 156, 455-465

Clausnitzer V, Hopmans J 1994 Simultaneous modeling of transient three-dimensional root growth and soil water flow. Plant Soil 164, 299-314

Delory BM, Baudson C, Brostaux Y, Lobet G, Du Jardin P, Pagès L, Delaplace P 2016 archiDART: an R package for the automated computation of plant root architectural traits. Plant Soil 398, 351-365

Diggle AJ 1988 ROOTMAP - a model in three-dimensional coordinates of the growth and structure of fibrous root systems. Plant Soil 105, 169-178

Doussan C, Pierret A, Garrigues E, Pagès L 2006 Water uptake by plant roots: II-Modelling of water transfer int he soil root-system with explicit accoutn of flow within the root system - Comparison with experiments. Plant Soil 283, 99-117 
Draye X 2002 Consequences of root growth kinetics and vascular structure on the distribution of lateral roots. Plant, Cell Environ. 25, 1463-1474

Dunbabin V, Diggle AJ, Rengel Z, van Hugten R 2002 Modelling the interactions between water and nutrient uptake and root growth. Plant Soil 239, 19-38

Dunbabin VM, Postma JA, Schnepf A, Pagès L, Javaux M, Wu L, Leitner D, Chen YL, Rengel Z, Diggle AJ 2013 Modelling root-soil interactions using three-dimensional models of root growth, architecture and function. Plant Soil 372, 93-124

Fitter A, Stickland T, Harvey M, Wilson G 1991 Architectural analysis of plant root systems 1. Architectural correlates of exploitation efficiency. New Phytol.118, 375-382

Forde BG 2009 Is it good noise? The role of developmental instability in the shaping of a root system. J. Exp. Bot. $60,3989-4002$

Gao S, Pan WL, Koenig RT 1998 Integrated root system age in relation to plant nutrient uptake activity. Agron. J. $90,505-510$

Ge Z, Rubio G, Lynch JP 2000 The importance of root gravitropism for inter-root competition and phosphorus acquisition efficiency: results from a geometric simulation model. Plant Soil 218, 159-171

Hargreaves CE, Gregory PJ, Bengough AG 2009 Measuring root traits in barley (Hordeum vulgare ssp. vulgare and ssp. spontaneum) seedlings using gel chambers, soil sacs and X-ray microtomography. Plant Soil 316, 285297

Ito K, Tanakamaru K, Morita S, Abe J, Inanaga S 2006 Lateral root development, including responses to soil drying, of maize (Zea mays) and wheat (Triticum aestivum) seminal roots. Physiol. Plant. 127, 260-267

Javaux M, Schröder T, Vanderborght J, Vereecken H 2008 Use of a Three-Dimensional Detailed Modeling Approach for Predicting Root Water Uptake. Vadose Zone J. 7, 1079-1079

Judd LA, Jackson BE, Fonteno WC 2015 Advancements in root growth measurement technologies and observation capabilities for container-grown plants. Plants 4, 369-392

Kuchenbuch R, Ingram K 2002 Image analysis for non-destructive and non-invasive quantification of root growth and soilw ater content in rhizotrons. J. Plant Nutr. Soil Sci. 165, 573-581

Kuijken RC, van Eeuwijk FA, Marcelis LF, Bouwmeester HJ 2015 Root phenotyping: from component trait in the lab to breeding. J. Exp. Bot. 66, 5389-5401 
Kutschera L 1960 Wurzelatlas mitteleuropäischer Ackerunkräuter und Kulturpflanzen. DLG-Verlag, Frankfurt/Main. pp. 124,574

Kutschera L, Lichtenegger E, Sobotik M 2009 Wurzelatlas der Kulturpflanzen gemäßigter Gebiete: mit Arten des Feldgemüsebaues. DLG-Verlag Frankfurt/Main. pp. 222, 226-227

Landl M, Huber K, Schnepf A, Vanderborght J, Javaux M, Bengough AG, Vereecken H 2017 A new model for root growth in soil with macropores. Plant Soil 415, 99-116

Le Bot J, Serra V, Fabre J, Draye X, Adamowicz S, Pagès L 2010 DART: a software to analyse root system architecture and development from captured images. Plant Soil 326, 261-273

Leitner D, Felderer B, Vontobel P, Schnepf A 2014 Recovering root system traits using image analysis exemplified by two-dimensional neutron radiography images of lupine. Plant Physiol 164, 24-35

Leitner D, Klepsch S, Bodner G, Schnepf A 2010 A dynamic root system growth model based on L-Systems. Plant Soil 332, 177-192

Liang J, Zhang J, Wong M 1996 Effects of air-filled soil porosity and aeration on the initiation and growth of secondary roots of maize (Zea mays). Plant Soil 186, 245-254

Lynch JP 2007 Roots of the second green revolution. Aust. J. Bot. 55, 493-512

Lynch JP, Nielsen KL, Davis RD, Jablokow AG 1997 SimRoot: modelling and visualization of root systems. Plant Soil 188, 139-151

Mairhofer S, Zappala S, Tracy SR, Sturrock C, Bennett M, Mooney SJ, Pridmore T 2012 RooTrak: automated recovery of three-dimensional plant root architecture in soil from X-ray microcomputed tomography images using visual tracking. Plant Physiol 158, 561-569

Mooney SJ, Pridmore TP, Helliwell J, Bennett MJ 2012 Developing X-ray computed tomography to non-invasively image 3-D root systems architecture in soil. Plant Soil 352, 1-22

Nagel K, Putz A, Gilmer F, Heinz K, Fischbach A, Pfeifer J, Faget M, Bloßfeld S, Ernst M, Dimaki C, Kastenholz B, Kleinert A, Galinski A, Scharr H, Fiorani F, Schurr U 2012 GROWSCREEN-Rhizo is a novel phenotyping robot enablign simultaneous measruements of root and shoot growth for pkants grown in soil-filled rhizotrons. Funct. Plant Biol. 39, 891-904

Nagel KA, Bonnett D, Furbank R, Walter A, Schurr U, Watt M 2015 Simultaneous effects of leaf irradiance and soil moisture on growth and root system architecture of novel wheat genotypes: implications for phenotyping. J. Exp. Bot. 66, 5441-5452 
Nakamoto T 1994 Plagiogravitropism of maize roots. Plant Soil 165: 327-332.

Nye PH, Tinker PB 1977 Solute movement in the soil-root system. Univ of California Press. pp. 342

Pagès L 2011 Links between root developmental traits and foraging performance. Plant, Cell Environ. 34, 1749-1760

Pagès L, Pellerin S 1994 Evaluation of parameters describing the root system architecture of field grown maize plants (Zea mays L.),II. Plant Soil 164, 169-176

Pagès L, Picon-Cochard, Catherine 2014 Modelling the root system architecture of Poaceae. Can we simulate integrated traits from morphological parameters of growth and branching? New Phytol.204, 149-158

Pagès L, Vercambre G, Drouet J-L, Lecompte F, Collet C, Le Bot J 2004 Root Typ: a generic model to depict and analyse the root system architecture. Plant Soil 258, 103-119

Pellerin S, Pagès L 1994 Evaluation of parameters describing the root system architecture of field grown maize plants (Zea mays L.), I. Plant Soil 164, 155-167

Pellerin S, Tabourel F 1995 Length of the apical unbranched zone of maize axile roots: its relationship to root elongation rate. Environ. Exp. Bot. 35, 193-200

Pohlmeier A, Javaux M, Vereecken H, Haber-Pohlmeier S 2013 Magnetic resonance imaging techniques for visualization of root growth and root water uptake processes. In: S. H. Anderson, J. W. Hopmans, editors, Soil-Water-Root Processes: Advances in Tomography and Imaging. pp. 137-156. SSSA Spec. Publ. 61

Popova L, van Dusschoten D, Nagel KA, Fiorani F, Mazzolai B 2016 Plant root tortuosity: an indicator of root path formation in soil with different composition and density. Ann. Bot. 118, 685-698

Postma JA, Dathe A, Lynch JP 2014 The optimal lateral root branching density for maize depends on nitrogen and phosphorus availability. Plant Physiol 166, 590-602

Rascher U, Blossfeld S, Fiorani F, Jahnke S, Jansen M, Kuhn AJ, Matsubara S, Märtin LL, Merchant A, Metzner R 2011 Non-invasive approaches for phenotyping of enhanced performance traits in bean. Funct. Plant Biol. $38,968-983$

Rich S, Watt M 2013 Soil conditions and cereal root system architecture: review and considerations for linking Darwin and Weaver. J. Exp. Bot. 64, 1193-1208

Roose T, Schnepf A 2008 Mathematical models of plant-soil interaction. Philos. Trans. R. Soc., A 366, 4597-4611

Schenk M, Barber S 1979 Phosphate uptake by corn as affected by soil characteristics and root morphology. Soil Sci. Soc. Am. J. 43, 880-883 
Smith S, De Smet I 2012 Root system architecture: insights from Arabidopsis and cereal crops. Philos. Trans. R. Soc., B 367, 1441-1452

Tardieu F, Pellerin S 1990 Trajectory of the nodal roots of maize in fields with low mechanical constraints. Plant Soil 124, 39-45

Tracy SR, Black CR, Roberts JA, Sturrock C, Mairhofer S, Craigon J, Mooney SJ 2012 Quantifying the impact of soil compaction on root system architecture in tomato (Solanum lycopersicum) by X-ray micro-computed tomography. Ann. Bot. 110, 511-519

Tracy SR, Roberts JA, Black CR, McNeill A, Davidson R, Mooney SJ 2010 The X-factor: visualizing undisturbed root architecture in soils using X-ray computed tomography. J. Exp. Bot. 61, 311-313

Tricot F, Crozat Y, Pellerin S 1997 Root system growth and nodule establishment on pea (Pisum sativum L.). J. Exp. Bot. 48, 1935-1941

Volder A, Smart DR, Bloom AJ, Eissenstat DM 2005 Rapid decline in nitrate uptake and respiration with age in fine lateral roots of grape: implications for root efficiency and competitive effectiveness. New Phytol.165, 493502

Weaver JE, Jean FC, Crist JW 1922 Development and activities of roots of crop plants: a study in crop ecology. Agronomy \& Horticulture -- Faculty Publications. Paper 511

Weaver JE, Kramer J, Reed M 1924 Development of Root and Shoot of Winter Wheat Under Field Environment. Ecology 5, 26-50

Wenzel WW, Wieshammer G, Fitz WJ, Puschenreiter M 2001 Novel rhizobox design to assess rhizosphere characteristics at high spatial resolution. Plant Soil 237, 37-45

Wu J, Pagès L, Wu Q, Yang B, Guo Y 2015 Three-dimensional architecture of axile roots of field-grown maize. Plant Soil 387, 363-377

Wu L, McGechan M, McRoberts N, Baddeley J, Watson C 2007 SPACSYS: integration of a 3D root architecture component to carbon, nitrogen and water cycling—model description. Ecol. Modell. 200, 343-359

Wu L, McGechan M, Watson C, Baddeley J 2005 Developing existing plant root system architecture models to meet future agricultural challenges. Adv. Agron. 85, 181-219

Yu P, Gutjahr C, Li C, Hochholdinger F 2016 Genetic control of lateral root formation in cereals. Trends Plant Sci. 21, 951-961 

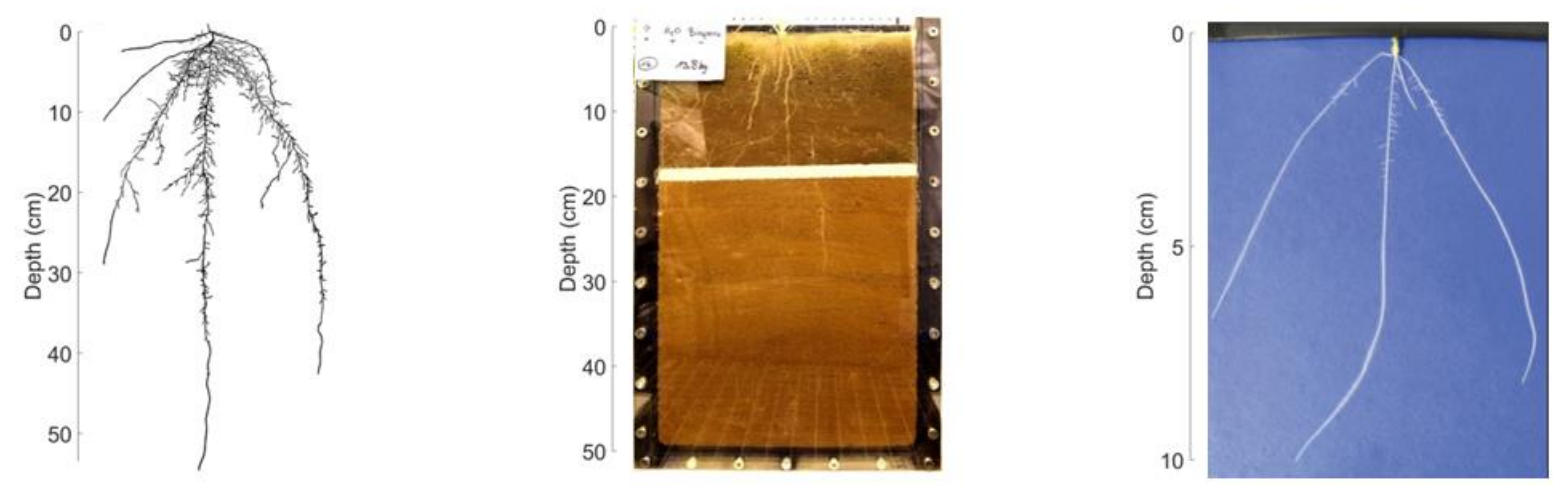

Fig. 1: Example images for each data source: (a) root drawing, (b) rhizotron image, (c) image of roots grown on germination paper

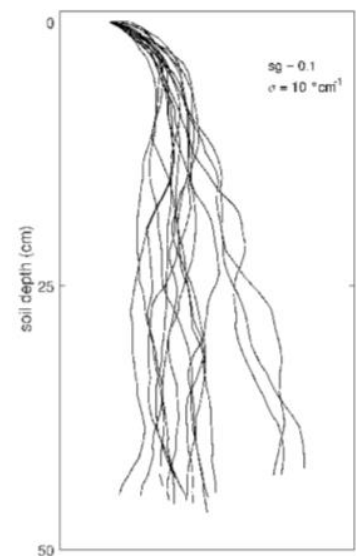

Fig. 2: Example of simulated axial root trajectories
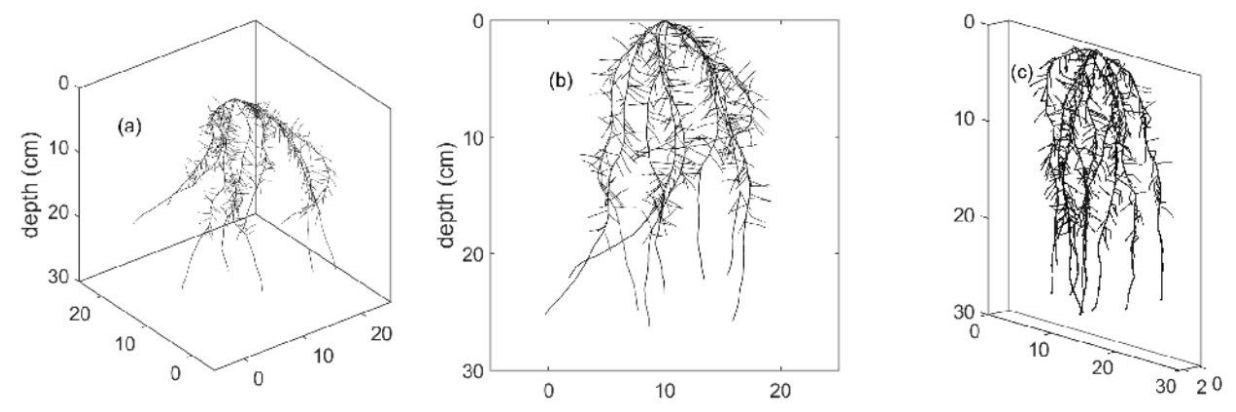

Fig. 3: (a) unconstrained root growth in 3D, (b) unconstrained root growth projected onto $x-z$ plane, (c) constrained root growth in a rhizotron 


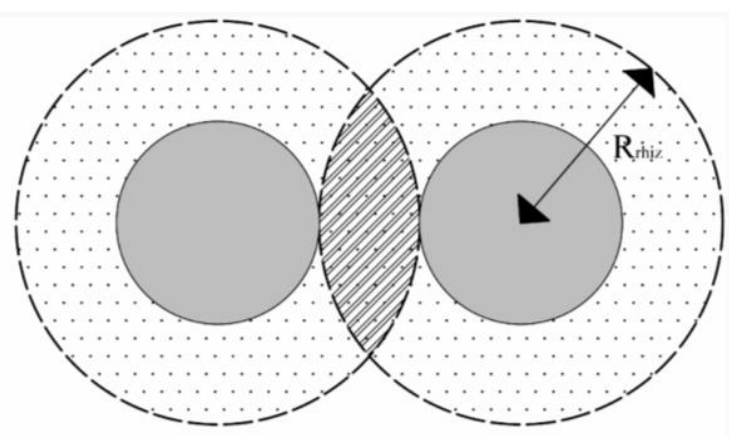

cross-section through roots

$\therefore \cdots$ net rhizosphere volume

overlap volume

Fig. 4: Schematic representation of rhizosphere volume, overlap volume and rhizosphere radius $\mathrm{R}_{\text {rhiz }}$ : grey circles represent cross-sections through two individual roots, dotted and diagonal hatching show net rhizosphere and overlap volume, respectively
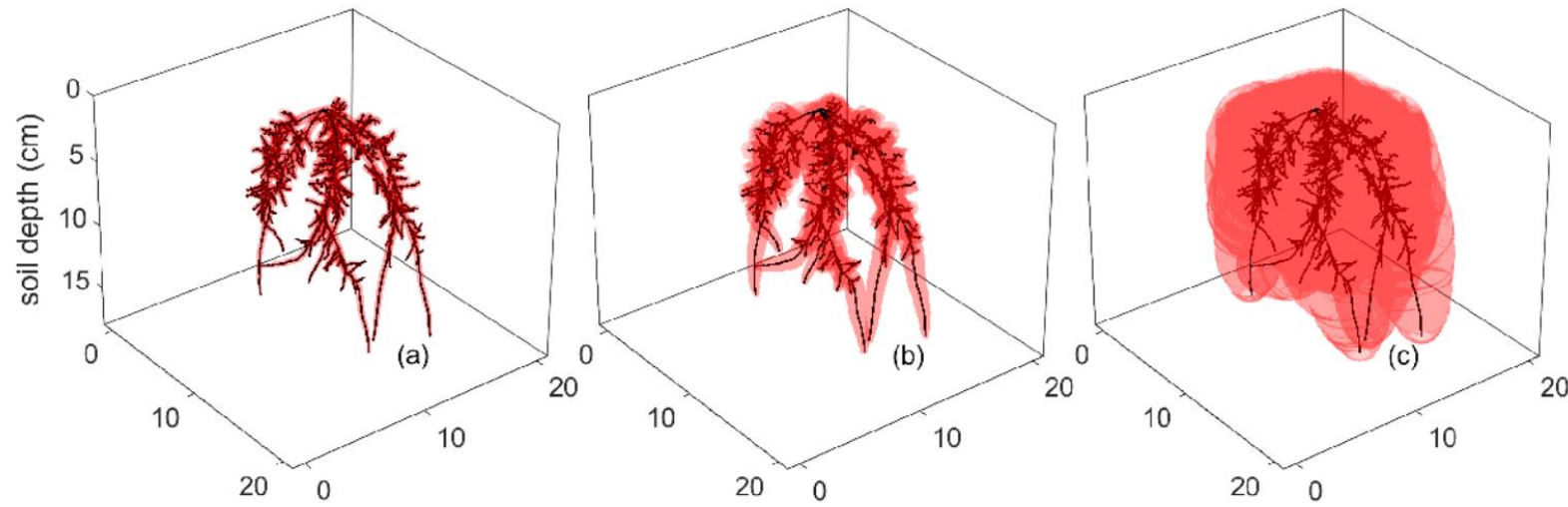

Fig. 5: Representation of the computed 3D root system (black) with rhizosphere zone (red) for simulations with $\mathrm{D}_{\mathrm{e}}=$ $10^{-8} \mathrm{~cm}^{2} \mathrm{~s}^{-1}(\mathrm{a}), \mathrm{D}_{\mathrm{e}}=10^{-7} \mathrm{~cm}^{2} \mathrm{~s}^{-1}(\mathrm{~b})$ and $\mathrm{D}_{\mathrm{e}}=2 \times 10^{-6} \mathrm{~cm}^{2} \mathrm{~s}^{-1}(\mathrm{c})$ at day 30 

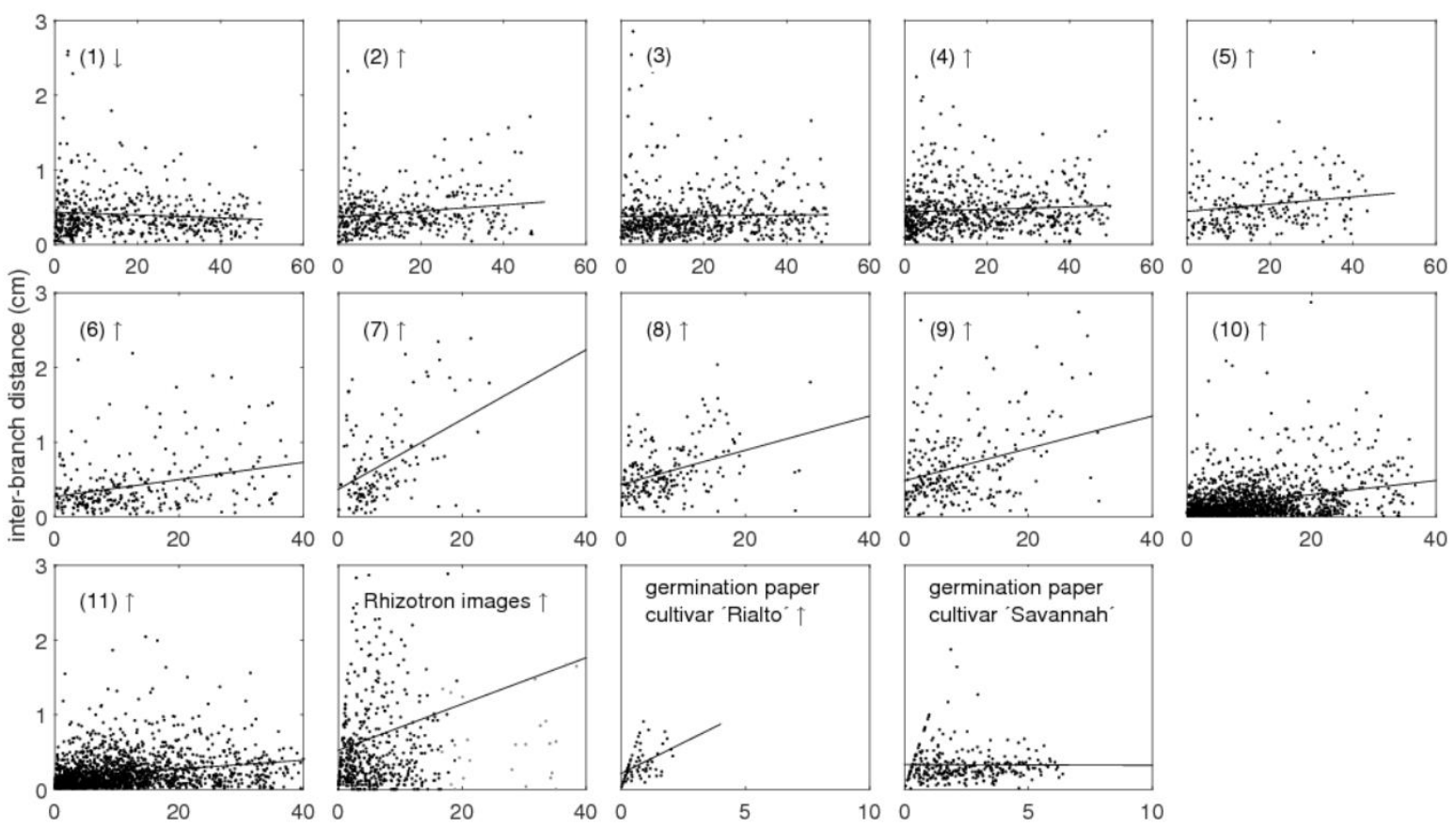

40

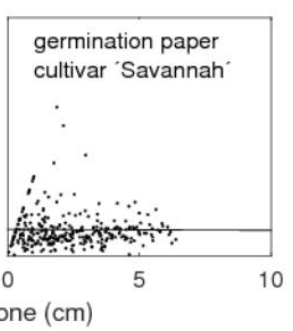

Fig. 6: Relationship between inter-branch distance and distance from the base of the branched zone illustrated for each data source; arrows indicate a significant up- respectively downward trend in the data set; the number codes for data sources one to eleven are found in Table 2
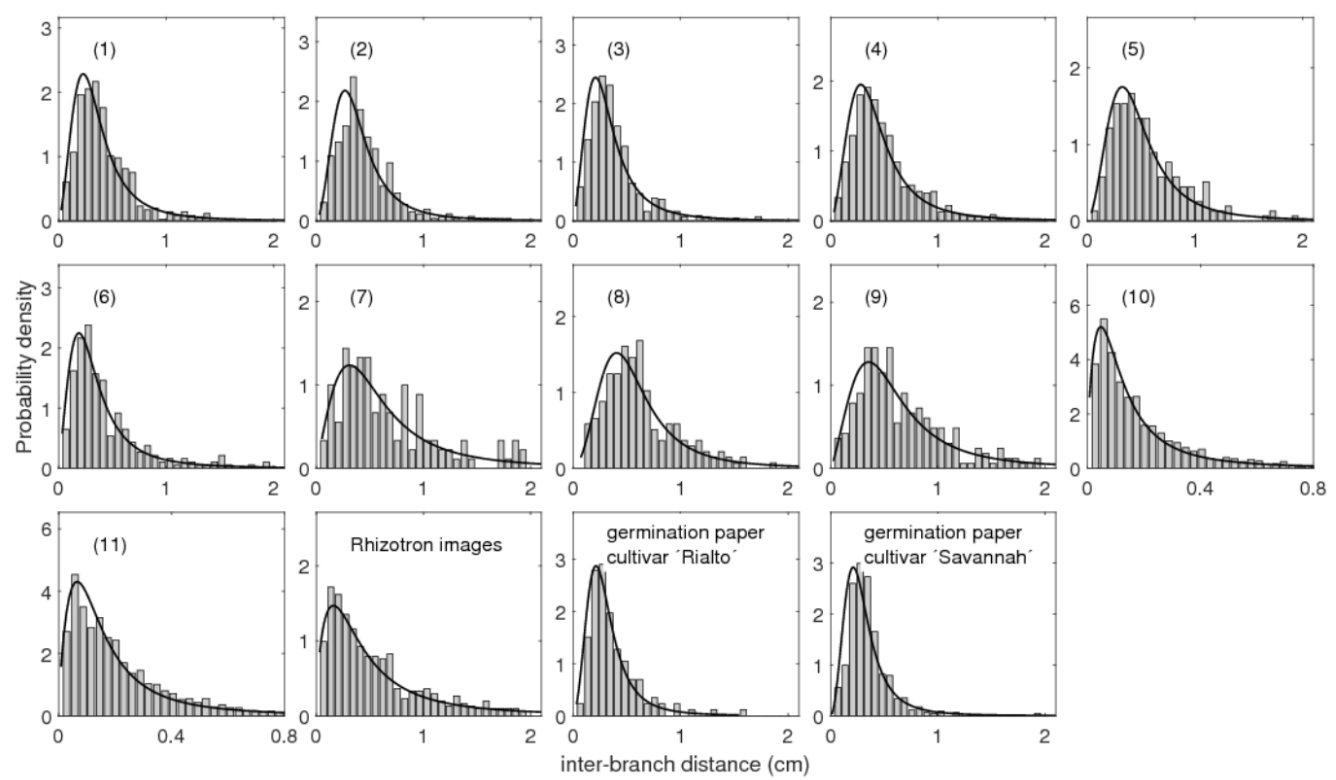

Fig. 7: Probability distributions of inter-branch distances with fitted lognormal functions illustrated for each data source; data sets were plotted using different scales for $\mathrm{x}$ - and $\mathrm{y}$-axis; the number codes for data sources one to eleven are found in Table 2 


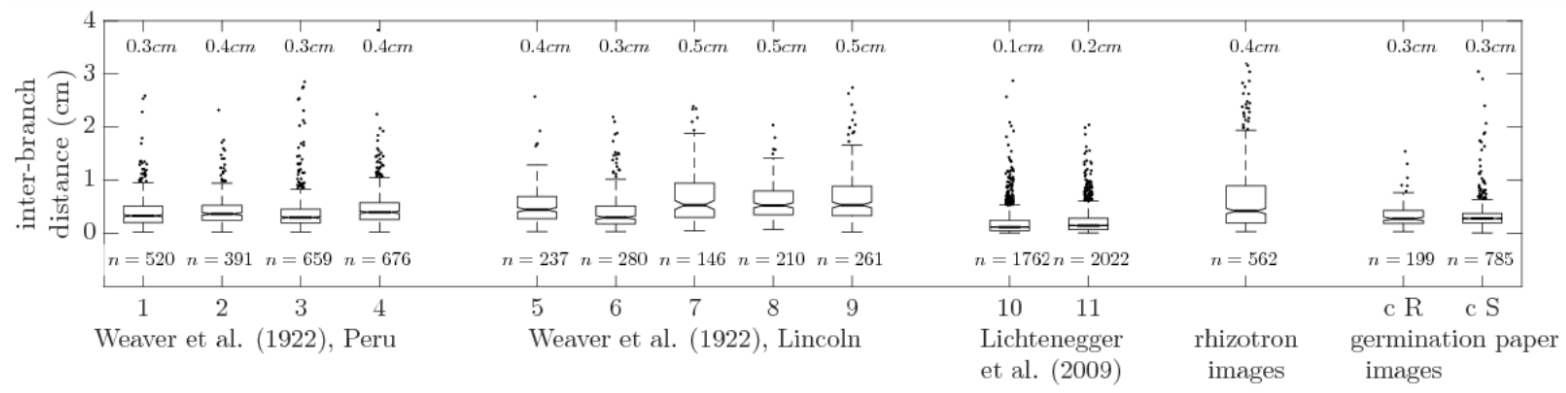

Fig. 8: Variation of inter-branch distances, medians and sample sizes (n) for the different data sources; the number codes for data sources one to eleven are found in Table 2; cR...cultivar Rialto, cS... cultivar Savannah
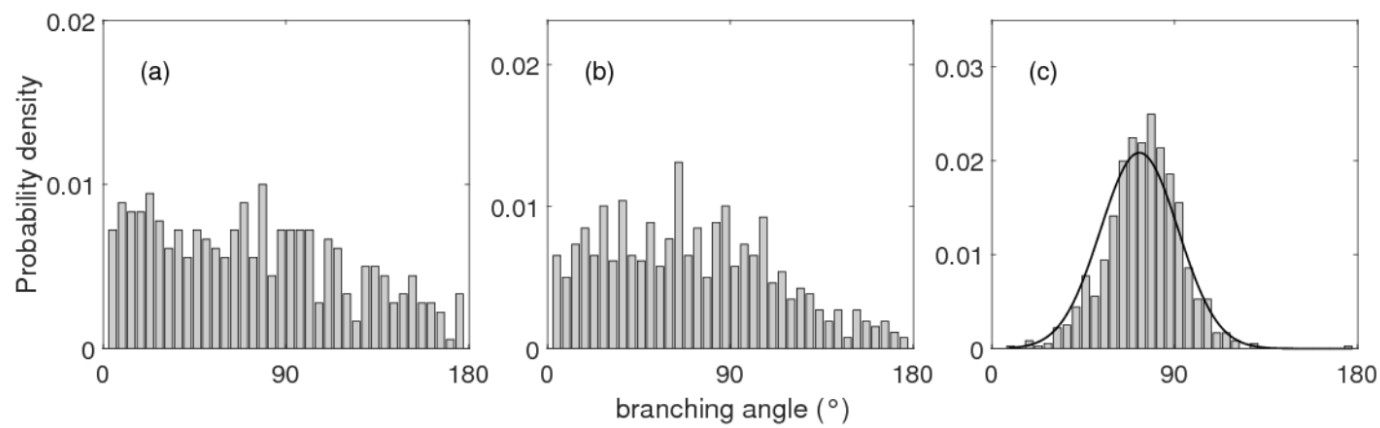

Fig. 9: Examples of probability distributions of branching angles for (a) a root drawing, (b) a rhizotron image, (c) an image of roots grown on germination paper with fitted normal function

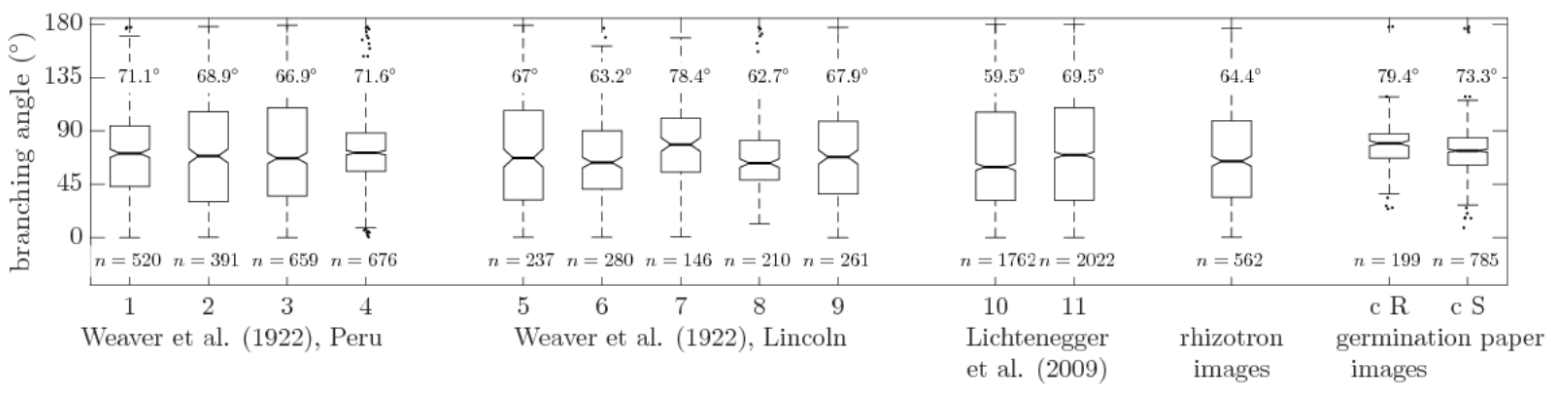

Fig. 10: Variation of branching angles, medians and sample sizes (n) for the different data sources; the number codes for data sources one to eleven are found in Table 2; cR...cultivar Rialto, cS... cultivar Savannah
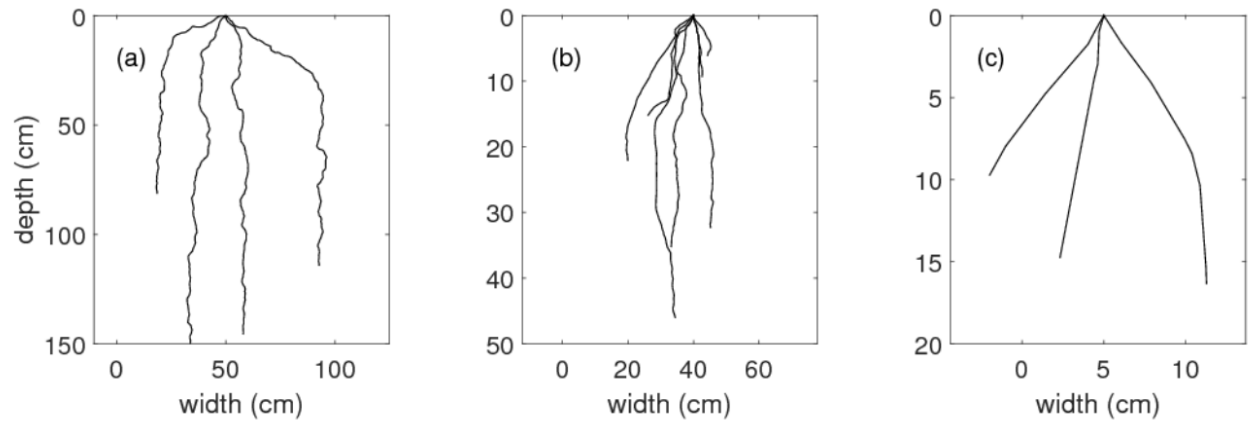

Fig. 11: Examples of reconstructed root growth trajectories of the axial roots for (a) a root drawing, (b) a rhizotron image, (c) an image of roots grown on germination paper 

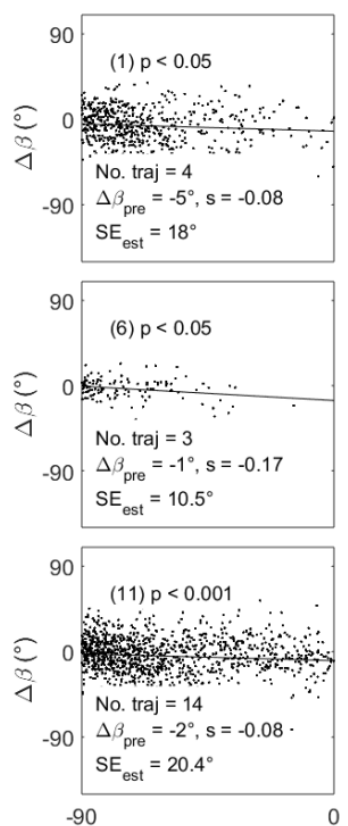

$\beta\left({ }^{\circ}\right)$
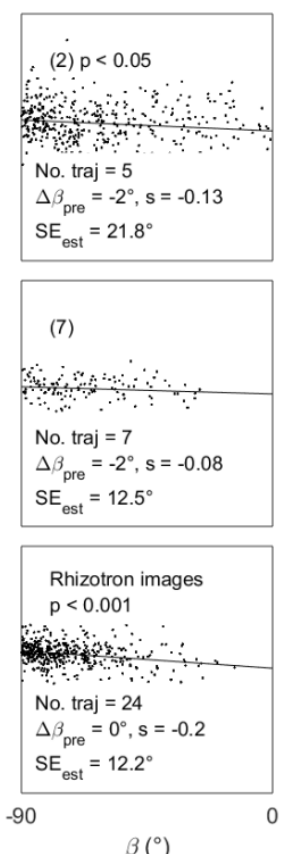
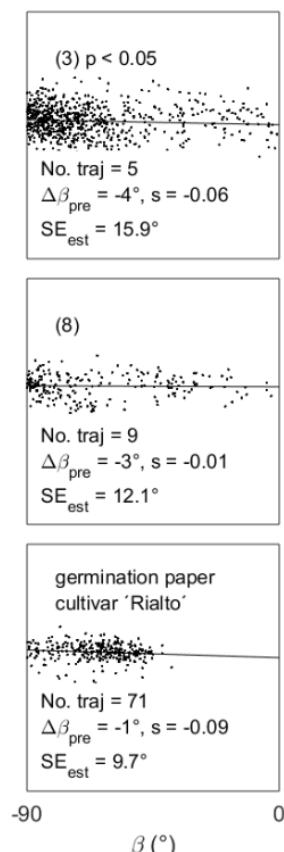
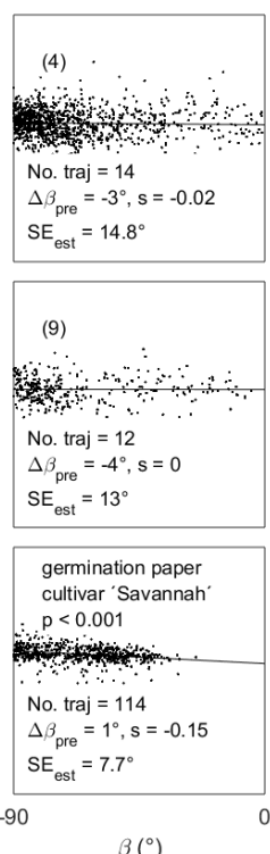
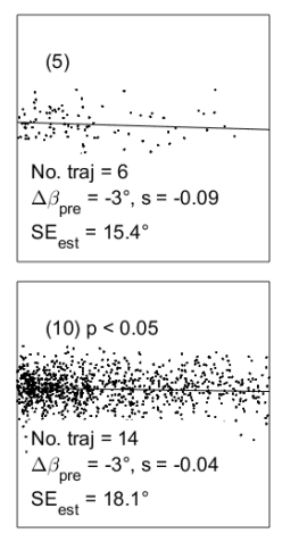

$\Delta \beta_{\text {pre }}=-3^{\circ}, \mathrm{s}=-0.04$
$\mathrm{SE}_{\mathrm{est}}=18.1^{\circ}$

(1)

Fig. 12: Relationship between reorientation angle $\Delta \beta$ and angle of the previous $1 \mathrm{~cm}$ long axial root section $\beta$ for each data source; $\Delta \beta_{\text {pre }} \ldots \Delta \beta$ predicted by regression at $\beta=-90^{\circ} ;$ s...slope, SEest... standard error of the estimate; No. traj ... number of analyzed trajectories; the number codes for data sources one to eleven are found in Table 2
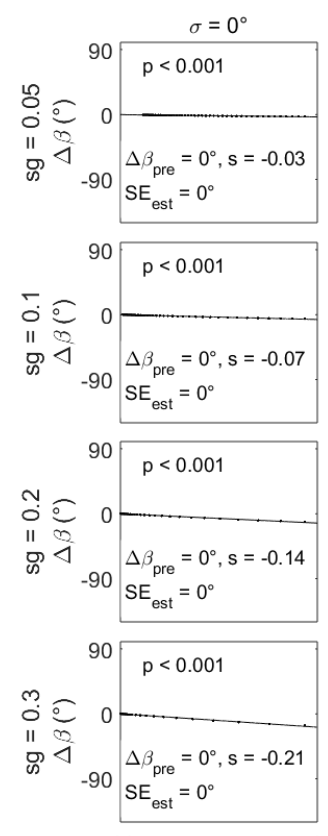

$\beta\left(^{\circ}\right)$
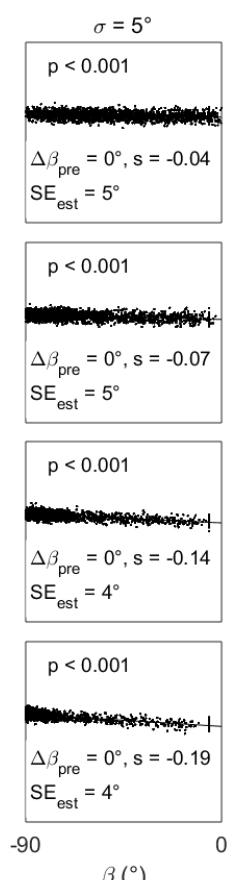
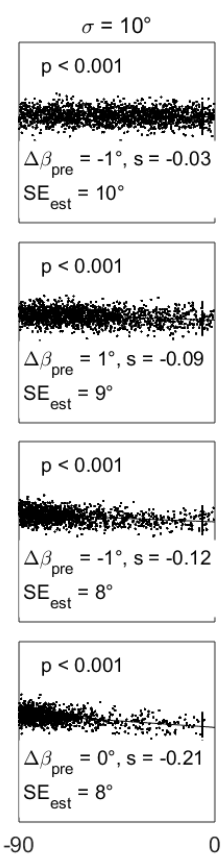

$\beta\left({ }^{\circ}\right)$
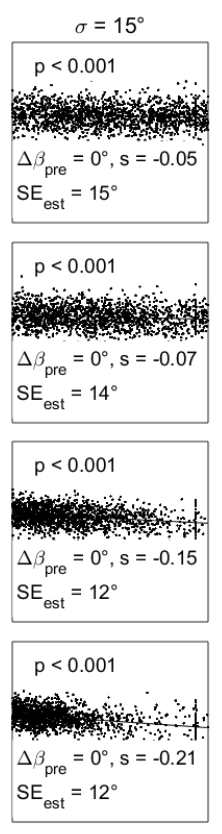

$-90$
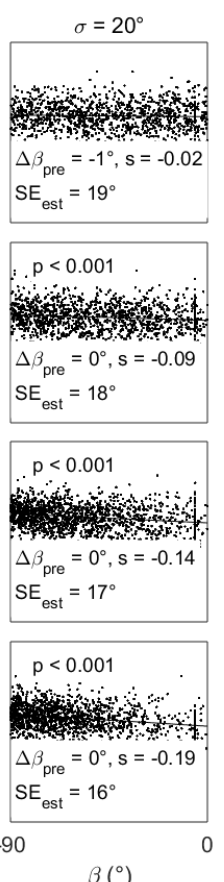

Fig. 13: Relationship between reorientation angle $\Delta \beta$ and angle of the previous $1 \mathrm{~cm}$ long axial root section $\beta$ for simulated root systems using different parametrizations of the sensitivity to gravitropism sg and the unit standard 
deviation of the random angle $\sigma ; \Delta \beta_{\text {pre }} \ldots \Delta \beta$ predicted by regression at $\beta=-90^{\circ}$, s...slope, $\mathrm{SE}_{\mathrm{est}} \ldots$ standard error of the estimate 


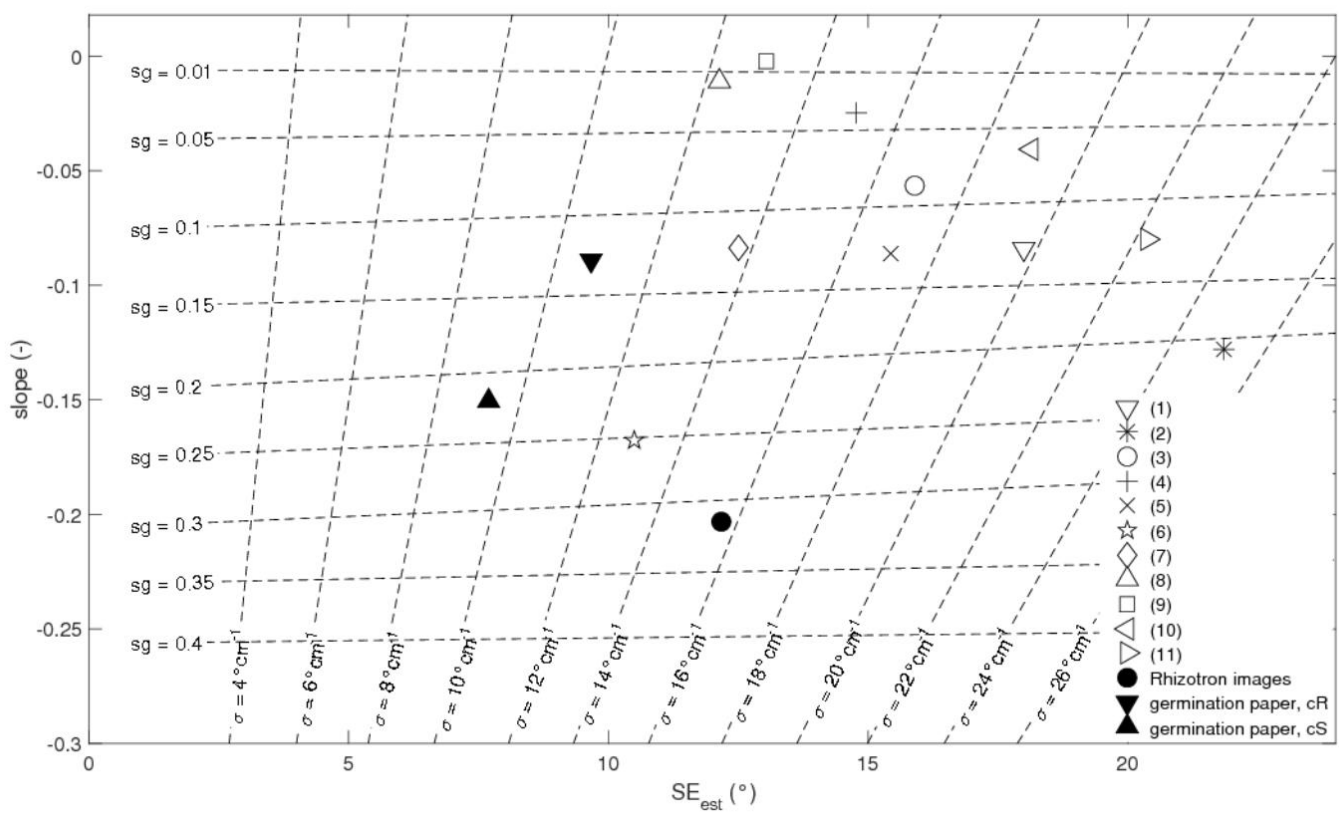

Fig. 14: Characteristic curves for the deduction of the gravitropism parameter sg and the tortuosity parameter $\sigma$ from the properties of the regression line (standard error of the estimate $\mathrm{SE}_{\text {est }}$ and slope) that relates root reorientation and root angle. The value pair of regression line properties of each data source deduced from Fig. 12 is inserted into the graph; the number codes for data sources one to eleven are found in Table 2
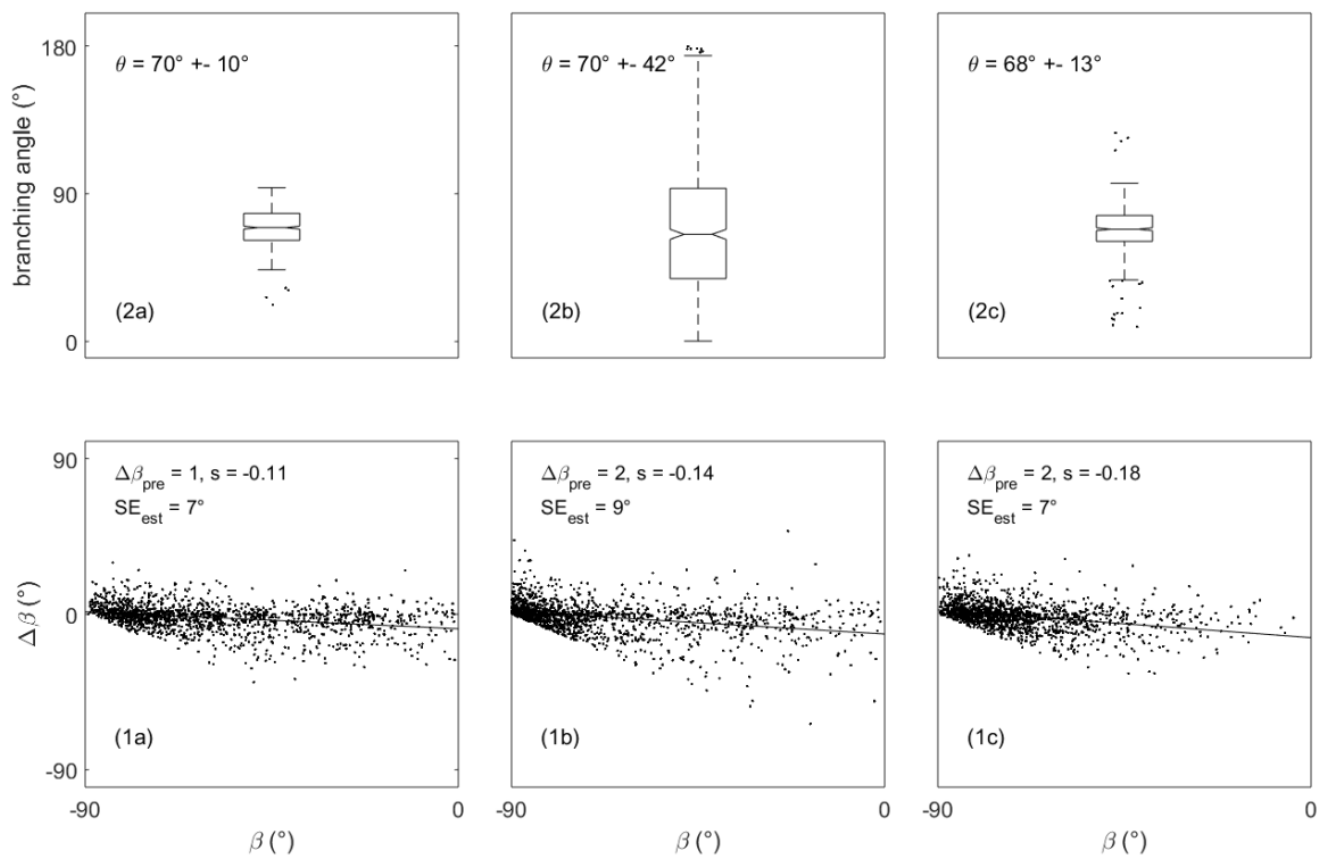

Fig. 15: (1) Branching angle $\theta$ (mean + - standard deviation) and (2) relationship between reorientation angle $\Delta \beta$ and angle of the previous $1 \mathrm{~cm}$ long axile root section $\beta$ with $\Delta \beta_{\text {pre }} \ldots \Delta \beta$ predicted by regression at $\beta=-90^{\circ}$, s...slope, $\mathrm{SE}_{\text {est }} \ldots$ standard error of the estimate for (a) unconstrained root growth in $3 \mathrm{D}$, (b) unconstrained root growth projected onto the x-z plane and (c) constrained root growth in a rhizotron (Fig. 3) 

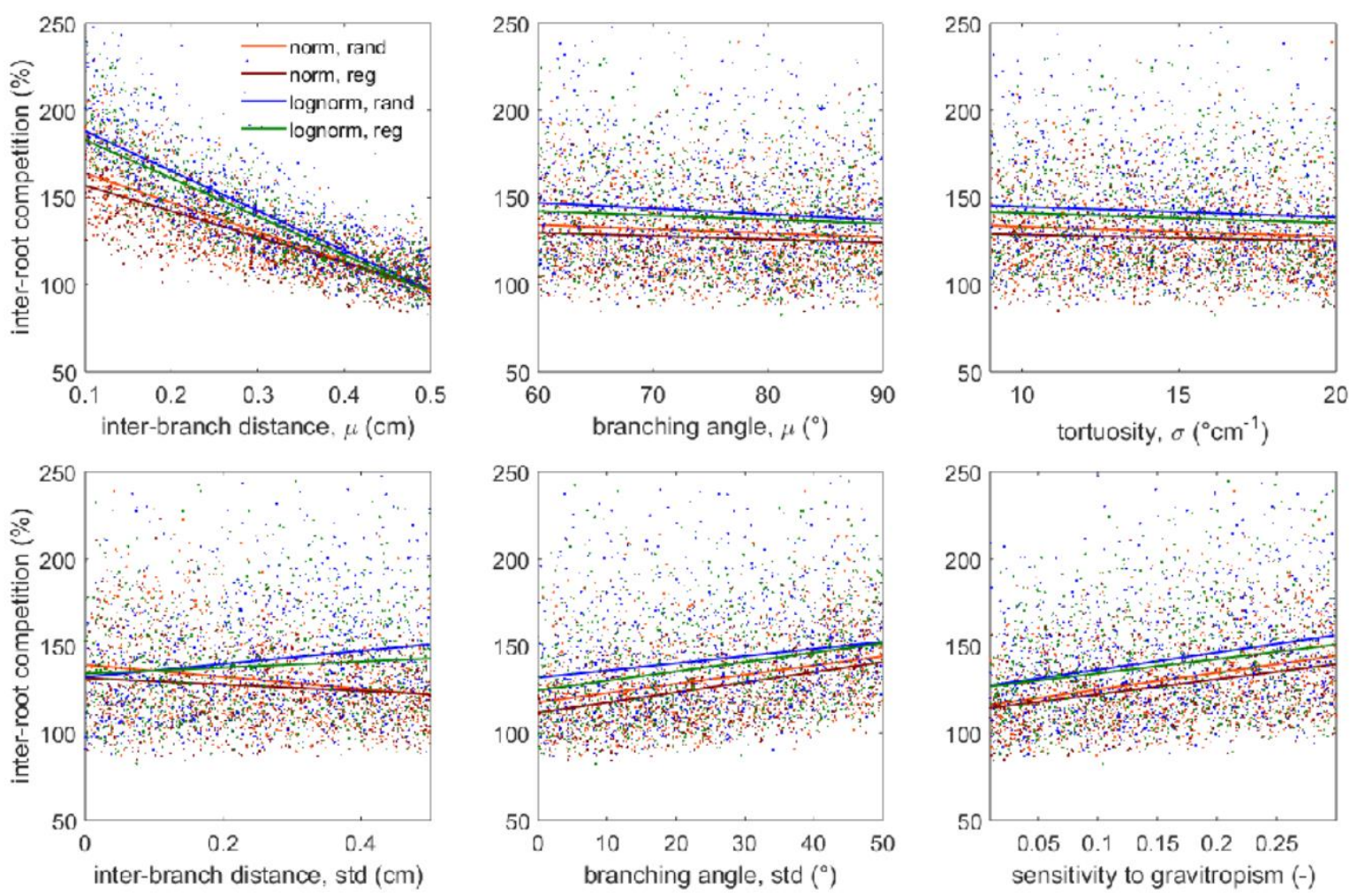

Fig. 16: Scatter plots with linear regression lines illustrating the relationships between inter-root competition and different parametrization factors for $D_{e}=10^{-8} \mathrm{~cm}^{2} \mathrm{~s}^{-1} ; \mu \ldots$ mean value, std... standard deviation, norm / lognorm... normally / lognormally distributed inter-branch distances, rand / reg... random / regular alignment of $1^{\text {st }}$ order laterals around the root axis 
Table 1: Overview of the parametrization of the root traits inter-branch distance, branching angle and directional orientation of root segments in the different $3 \mathrm{D}$ root architecture models; L...length unit, T... time unit

\begin{tabular}{|c|c|c|c|c|c|c|}
\hline & $\begin{array}{l}\text { RootTyp } \\
\text { (Pagès et al. } \\
2004 \text { ) }\end{array}$ & $\begin{array}{l}\text { SimRoot } \\
\text { (Lynch et al. } \\
1997 \text { ) }\end{array}$ & $\begin{array}{l}\text { ROOTMAP } \\
\text { (Diggle 1988) }\end{array}$ & $\begin{array}{l}\text { SPACSYS } \\
\text { (Wu et al. 2007) }\end{array}$ & $\begin{array}{l}\text { R-SWMS } \\
\text { (Javaux et al. 2008) }\end{array}$ & $\begin{array}{l}\text { RootBox } \\
\text { (Leitner et al. 2010) }\end{array}$ \\
\hline $\begin{array}{l}\text { Inter-branch } \\
\text { distance }\end{array}$ & $\begin{array}{l}\text { Fixed value or } \\
\text { increasing values } \\
\text { with depth }(\mathrm{L}) \\
\text { specified for each } \\
\text { root order }\end{array}$ & $\begin{array}{l}\text { Fixed value }(\mathrm{L}) \\
\text { specified for each } \\
\text { root order }\end{array}$ & $\begin{array}{l}\text { Fixed value }(\mathrm{L}) \\
\text { specified for each root } \\
\text { order }\end{array}$ & $\begin{array}{l}\text { Fixed value }(\mathrm{L}) \\
\text { specified for each } \\
\text { root order }\end{array}$ & $\begin{array}{l}\text { Fixed value }(\mathrm{T}) \text { specified } \\
\text { for each root order (inter- } \\
\text { branch distance is then also } \\
\text { a function of root growth } \\
\text { rate) }\end{array}$ & $\begin{array}{l}\text { Drawn from truncated } \\
\text { normal distribution }(\mathrm{L}) \\
\text { with mean and standard } \\
\text { deviation specified for } \\
\text { each order }\end{array}$ \\
\hline $\begin{array}{l}\text { Branching } \\
\text { angle }\end{array}$ & $\begin{array}{l}\text { Drawn from } \\
\text { normal } \\
\text { distribution with } \\
\text { mean and } \\
\text { standard } \\
\text { deviation } \\
\text { specified for each } \\
\text { root order }\end{array}$ & $\begin{array}{l}\text { Fixed value } \\
\text { specified for each } \\
\text { root order }\end{array}$ & $\begin{array}{l}\text { Fixed at } 90^{\circ} \text { to its } \\
\text { parent root }\end{array}$ & $\begin{array}{l}\text { Initial value with } \\
\text { random variation } \\
\text { within a predefined } \\
\text { range }\end{array}$ & $\begin{array}{l}\text { Fixed value specified for } \\
\text { each root order }\end{array}$ & $\begin{array}{l}\text { Drawn from normal } \\
\text { distribution with mean and } \\
\text { standard deviation } \\
\text { specified for each order }\end{array}$ \\
\hline $\begin{array}{l}\text { Directional } \\
\text { orientation } \\
\text { of root } \\
\text { segments }\end{array}$ & $\begin{array}{l}\text { Computed from } \\
\text { the direction of } \\
\text { the previous root } \\
\text { segment, different } \\
\text { selectable } \\
\text { tropisms and a } \\
\text { random } \\
\text { deflection angle }\end{array}$ & $\begin{array}{l}\text { Computed from } \\
\text { the direction of } \\
\text { the previous root } \\
\text { segment, } \\
\text { gravitropism and } \\
\text { a random } \\
\text { deflection angle }\end{array}$ & $\begin{array}{l}\text { Stochastically } \\
\text { determined with the } \\
\text { help of a random } \\
\text { deflection angle that } \\
\text { is calculated on the } \\
\text { basis of a user defined } \\
\text { probability and a } \\
\text { gravitropism index }\end{array}$ & $\begin{array}{l}\text { Computed from the } \\
\text { direction of the } \\
\text { previous root } \\
\text { segment, } \\
\text { gravitropism and a } \\
\text { random deflection } \\
\text { angle, which is } \\
\text { scaled with the } \\
\text { maximum root } \\
\text { segment length }\end{array}$ & $\begin{array}{l}\text { Computed from the } \\
\text { direction of the previous } \\
\text { root segment, } \\
\text { plagiogravitropism and a } \\
\text { random deflection angle, } \\
\text { which is scaled with the } \\
\text { maximum root segment } \\
\text { length }\end{array}$ & $\begin{array}{l}\text { A random angle, which is } \\
\text { scaled with the root } \\
\text { segment length, is added to } \\
\text { the growth direction of the } \\
\text { previous root segment; this } \\
\text { random angle is selected } \\
\text { for its directional } \\
\text { proximity to a desired } \\
\text { selectable tropism from a } \\
\text { specified number of } \\
\text { random angle realizations }\end{array}$ \\
\hline
\end{tabular}


Table 2: Description of image sources from literature; SW...spring wheat, WW...winter wheat

\begin{tabular}{|c|c|c|c|c|}
\hline Image Number & Variety & $\begin{array}{l}\text { Root system age } \\
\text { (calendar days) }\end{array}$ & Location & Literature source \\
\hline 1 & SW & 60 & \multirow{4}{*}{$\begin{array}{c}\text { Peru, } \\
\text { Nebraska, US }\end{array}$} & \multirow{4}{*}{ Weaver et al. (1922) } \\
\hline 2 & SW & 70 & & \\
\hline 3 & SW & 93 & & \\
\hline 4 & SW & 93 & & \\
\hline 5 & WW & 20 & \multirow{5}{*}{$\begin{array}{l}\text { Lincoln, } \\
\text { Nebraska, US }\end{array}$} & \multirow{5}{*}{$\begin{array}{l}\text { Weaver et al. (1922), } \\
\text { Weaver et al. (1924) }\end{array}$} \\
\hline 6 & WW & 30 & & \\
\hline 7 & SW & 31 & & \\
\hline 8 & SW & 45 & & \\
\hline 9 & SW & 60 & & \\
\hline 10 & WW & 60 & St. Donat, & Kutschera (1960), \\
\hline 11 & WW & 60 & Carinthia, Austria & Kutschera et al. (2009) \\
\hline
\end{tabular}

Table 3: Parameter values for simulation; sg... sensitivity to gravitropism $(-), \sigma \ldots$ unit standard deviation of the random angle $\left({ }^{\circ} \mathrm{cm}^{-1}\right)$, parameter explanations can be found in Clausnitzer and Hopmans (1994)

\begin{tabular}{ll}
\hline Gravitropism component & Tortuosity component \\
\hline $\mathrm{sg}=[0.005 ; 0.01 ; 0.05 ; 0.1 ; 0.15 ;$ & $\sigma=0$ to 20, interval $=1$ \\
$0.2 ; 0.25 ; 0.3 ; 0.35 ; 0.4]$ & \\
\hline
\end{tabular}

Table 4: Variation intervals of focus parameters; parameter explanations are found in Leitner et al. (2010)

\begin{tabular}{llllll}
\hline Parameter & Factor & Unit & Root order & $\min$ & $\max$ \\
\hline Inter-branch distance & $\mu$ & $(\mathrm{cm})$ & Axial & 0.1 & 0.5 \\
& std & $(\mathrm{cm})$ & Axial & 0 & 0.5 \\
Branching angle & $\mu$ & $\left({ }^{\circ}\right)$ & $1^{\text {st }}$ order lateral & 60 & 90 \\
& std & $\left({ }^{\circ}\right)$ & $1^{\text {st }}$ order lateral & 0 & 50 \\
Root growth trajectories & std of random angle & $\left({ }^{\circ} \mathrm{cm}^{-1}\right)$ & Axial & 9 & 20 \\
& deflection / tortuosity & & Axial & 0.01 & 0.3 \\
& Sensitivity to gravitropism & $(-)$ & Normally / lognormally distributed inter-branch distance \\
& Additional factors: & Random / regular radial branching angle \\
\hline
\end{tabular}

Table 5: Constant parameter values; parameter explanations are found in Leitner et al. (2010)

\begin{tabular}{|c|c|c|c|c|c|}
\hline \multicolumn{2}{|l|}{ Parameter } & Unit & axis & $1^{\text {st }}$ order laterals & $2^{\text {nd }}$ order laterals \\
\hline \multicolumn{2}{|l|}{ Initial elongation rate } & $\left(\mathrm{cm} \mathrm{d}^{-1}\right)$ & $1.2^{\mathrm{a}}$ & $0.8^{\mathrm{a}}$ & $0.8^{\mathrm{a}}$ \\
\hline \multicolumn{2}{|l|}{ Root radius } & $(\mathrm{cm})$ & $0.038^{\mathrm{a}}$ & $0.027^{\mathrm{a}}$ & $0.027^{\mathrm{a}}$ \\
\hline \multicolumn{2}{|l|}{ Basal root zone } & $(\mathrm{cm})$ & 2 & $0.2^{\mathrm{c}}$ & 0.125 \\
\hline \multicolumn{2}{|l|}{ Apical root zone } & $(\mathrm{cm})$ & 6 & $0.3^{\mathrm{c}}$ & 0.125 \\
\hline \multicolumn{2}{|l|}{ Inter-branch distance } & $(\mathrm{cm})$ & $\mathrm{fp}$ & 0.25 & 0 \\
\hline \multicolumn{2}{|l|}{ Number of branches per root axis } & $(-)$ & 50 & $6^{\mathrm{c}}$ & 0 \\
\hline \multicolumn{2}{|l|}{ Insertion/Branching angle } & $\left({ }^{\circ}\right)$ & 70 & $\mathrm{fp}$ & 90 \\
\hline \multicolumn{2}{|l|}{ Tropism } & $(-)$ & Gravitropism & Exotropism & Exotropism \\
\hline Tropism sensitivity & $\mathrm{sg}$ & $(-)$ & $\mathrm{fp}$ & 0.1 & 0.1 \\
\hline std of random angle deflection & $\sigma$ & $\left({ }^{\circ} \mathrm{cm}^{-1}\right)$ & $\mathrm{fp}$ & 20 & 20 \\
\hline
\end{tabular}

fp... focus parameter, specified in Table 4

${ }^{a}$ based on Materechera et al. (1991)

${ }^{\mathrm{b}}$ based on Ito et al. (2006)

${ }^{c}$ derived from root lengths of $1^{\text {st }}$ order laterals given by Ito et al. (2006) 
Table 6: Correlation coefficients between inter-root competition and parametrization factors, bold characters represent significant values at $\mathrm{p}<0.05$

\begin{tabular}{|c|c|c|c|c|c|c|c|}
\hline & & ibd, $\mu$ & ibd, std & $\theta, \mu$ & $\theta$, std & $\sigma$ & $\mathrm{sg}$ \\
\hline \multirow{4}{*}{$\mathrm{D}_{\mathrm{e}}=10^{-8} \mathrm{~cm}^{2} \mathrm{~s}^{-1}$} & norm, rand & -0.78 & -0.20 & -0.08 & 0.30 & -0.07 & 0.32 \\
\hline & norm, reg & -0.76 & -0.12 & -0.07 & 0.36 & -0.05 & 0.32 \\
\hline & lognorm, rand & -0.81 & 0.17 & -0.09 & 0.18 & -0.06 & 0.26 \\
\hline & lognorm, reg & -0.83 & 0.08 & -0.07 & 0.25 & -0.06 & 0.22 \\
\hline \multirow{4}{*}{$\mathrm{D}_{\mathrm{e}}=10^{-7} \mathrm{~cm}^{2} \mathrm{~s}^{-1}$} & norm, rand & -0.81 & -0.25 & -0.02 & 0.16 & -0.07 & 0.32 \\
\hline & norm, reg & -0.80 & -0.17 & 0.01 & 0.20 & -0.06 & 0.32 \\
\hline & lognorm, rand & -0.82 & 0.12 & -0.03 & 0.09 & -0.05 & 0.27 \\
\hline & lognorm, reg & -0.85 & 0.03 & 0.00 & 0.13 & -0.08 & 0.24 \\
\hline \multirow{4}{*}{$D_{e}=2 \times 10^{-6} \mathrm{~cm}^{2} \mathrm{~s}^{-1}$} & norm, rand & -0.73 & -0.24 & 0.00 & 0.04 & -0.09 & 0.49 \\
\hline & norm, reg & -0.72 & -0.17 & 0.06 & 0.04 & -0.10 & 0.49 \\
\hline & lognorm, rand & -0.70 & 0.04 & 0.01 & 0.01 & -0.07 & 0.45 \\
\hline & lognorm, reg & -0.72 & -0.06 & 0.02 & 0.01 & -0.12 & 0.43 \\
\hline
\end{tabular}

norm / lognorm... normally / lognormally distributed inter-branch distances, rand / reg... random / regular alignment of $1^{\text {st }}$ order laterals around the root axis 